\title{
Cellular and Molecular Mechanisms of Diabetic Atherosclerosis: Herbal Medicines as a Potential Therapeutic Approach
}

\author{
Jinfan Tian, ${ }^{1}$ Yanfei Liu, ${ }^{2}$ Yue Liu, ${ }^{3}$ Keji Chen, ${ }^{3}$ and Shuzheng Lyu ${ }^{1}$ \\ ${ }^{1}$ Department of Cardiology, Beijing Anzhen Hospital, Capital Medical University, Beijing 100029, China \\ ${ }^{2}$ Graduate School, Beijing University of Chinese Medicine, Beijing 100029, China \\ ${ }^{3}$ Cardiovascular Disease Centre, Xiyuan Hospital, China Academy of Chinese Medical Sciences, Beijing 100091, China \\ Correspondence should be addressed to Yue Liu; liuyueheart@hotmail.com and Shuzheng Lyu; shuzheng@medmail.com.cn
}

Received 26 April 2017; Revised 30 June 2017; Accepted 10 July 2017; Published 13 August 2017

Academic Editor: Mariateresa Giuliano

Copyright (c) 2017 Jinfan Tian et al. This is an open access article distributed under the Creative Commons Attribution License, which permits unrestricted use, distribution, and reproduction in any medium, provided the original work is properly cited.

An increasing number of patients diagnosed with diabetes mellitus eventually develop severe coronary atherosclerosis disease. Both type 1 and type 2 diabetes mellitus increase the risk of cardiovascular disease associated with atherosclerosis. The cellular and molecular mechanisms affecting the incidence of diabetic atherosclerosis are still unclear, as are appropriate strategies for the prevention and treatment of diabetic atherosclerosis. In this review, we discuss progress in the study of herbs as potential therapeutic agents for diabetic atherosclerosis.

\section{Introduction}

Cardiovascular diseases (CVDs), including atherosclerosis, are important complications of diabetes and the leading causes of mortality in patients with diabetes. Systemic factors accompanying diabetes, such as dyslipidaemia and hypertension, are thought to affect the development of diabetic vascular diseases. In addition, insulin resistance and excess production of advanced glycosylation end products (AGEs) contribute to disorders of lipid metabolism, oxidative stress, endothelial dysfunction, monocyte recruitment, foam cell formation, phenotype changes in vascular smooth muscle cells (VSMCs), and thrombosis formation [1]. In addition, diabetes and atherosclerosis exhibit common pathologies, although the underlying mechanisms are still being explored.

Botanical and natural drugs have a long, documented history in treating diabetes and vascular diseases. The vascularprotective properties of herb medicines include their ability to scavenge free radicals, inhibit apoptosis, and reduce inflammation and platelet aggregation [2]. Most recently, Li et al. [3] uncovered the antidiabetes effect of artemisinins, and the mechanism involves driving the in vivo conversion of pancreatic cells into functional $\beta$-like cells by enhancing GABA signalling. Furthermore, owing to the multitarget effects and comprehensive sources of herbal medicines, it remains of utmost importance to improve our understanding of their potential use in the treatment of diabetes and diabetic atherosclerosis despite their reported side effects. Since diabetic atherosclerosis is a multifactorial disease, in this review, we first discuss the cellular and molecular mechanisms for the pathogenesis of diabetic atherosclerosis and then the progress in the study of herbs as potential therapeutic agents for diabetic atherosclerosis.

\section{Cell Types Involved in Diabetic Atherosclerosis}

2.1. Myeloid Cells. Diabetes and atherosclerosis are chronic inflammatory conditions. Myeloid cells (neutrophils, monocytes, and macrophages) are involved in both atherosclerosis and diabetes. The migration of circulating monocytes into the vessel wall is critical for the development of diabetic atherosclerosis. Moreover, intercellular cell adhesion molecule-1(ICAM-1), chemoattractant protein-1(MCP-1), and macrophage migration inhibitory factor (MIF), which regulate the adhesion of monocytes, are dysregulated in hyperglycemia-induced atherosclerosis in animal models. Increased foam cells derived from macrophages promote 
the acceleration of atherosclerotic lesions in diabetic $\mathrm{ApoE}^{-/-}$ mice $[4,5]$. A more inflammatory monocyte/macrophage phenotype with secretion of higher levels of proinflammatory cytokines was detected in both animal models and patients with diabetes mellitus [6]. Increases in long-chain acylCOA synthetase 1 (ACSL1), toll-like receptor (TLR) 2, and TLR4 contribute to the increased inflammatory monocyte/ macrophage phenotype in the context of diabetes [6]. Neutrophil infiltration also has a role in diabetic atherosclerosis. In addition, T-cell function is closely related to atherosclerosis in the diabetic environment, and inflammatory monocytes have been shown to activate Th17 cells under diabetic conditions [7].

2.2. Endothelial Cells. Endothelial dysfunction due to inflammation and oxidative stress is a crucial characteristic in diabetes mellitus-linked atherosclerosis. Endothelial dysfunction is associated with decreased nitric oxide (NO) availability, either through loss of NO production or NO biological activity $[8,9]$. The excess generation of free oxygen radicals leads to apoptosis in endothelial cells [9]. In hyperglycemia, chronic inflammation increases vascular permeability, promotes the generation of adhesion molecules and chemokines, and stimulates accumulation of monocytes in the artery wall. The interleukin-1 (IL-1) antagonist anakinra improves endothelial dysfunction in diabetic animals via attenuation of the proinflammatory enzymes cyclooxygenase (COX) and inducible nitric oxide synthase (iNOS) triggered by diabetes in the vascular wall $[10,11]$.

2.3. Smooth Muscle Cells. Proliferation and accumulation of smooth muscle cells are detected in both type 1 and type 2 diabetes mellitus. However, it is still unclear whether changes in smooth muscle cells are a result of the diabetic environment directly or are caused by endothelial injury and macrophage recruitment. According to a report by Chen et al. [12], various concentrations of glucose $(5.6,11.1,16.7$, and $22.2 \mathrm{mM}$ ) increase the proliferation of vascular smooth muscle cells (VSMCs) in a concentration-dependent manner after $48 \mathrm{~h}$ of incubation. Another study showed that after initial injury, growth factors and cytokines released by endothelial cells, inflammatory cells, and platelets promote changes in VSMC phenotypes, thereby enhancing VSMC proliferation and migration [13]. Additionally, aortic smooth muscle cells isolated from $\mathrm{NOX}^{-/} \mathrm{ApoE}^{-}$mice exhibit a dedifferentiated phenotype, including loss of contractile gene expression [14].

2.4. Platelets. Accumulating evidence has shown that platelet hyperreactivity is a crucial cause of diabetic atherosclerosis in both animal models and diabetic patients. Enhanced platelet aggregation and synthesis of thromboxane A2 were detected within days of streptozotocin- (STZ-) dependent induction of diabetes in a rat model [15]. Platelets from patients with diabetes have been shown to have decreased sensitivity to antiaggregation agents, such as prostacyclin (PGI2) and NO [16]. Glycated low-density lipoprotein- (GlyLDL-) and hyperinsulinemia-induced impairment of calcium homeostasis, activation of protein kinase $\mathrm{C}(\mathrm{PKC})$, increased generation of reactive oxygen species (ROS), and decreased NO bioactivity result in hyperactivation of platelets [17]. According to a report by Wang et al., a significant correlation between plasma CTRP9 concentrations (a novel adiponectin paralog) and platelet aggregation amplitude was observed in high-fat diet-induced diabetic C57BL/6J mice. Enhancing CTRP9 production and/or exogenous supplementation of CTRP9 may protect against diabetic cardiovascular injury via inhibition of abnormal platelet activity [18].

\section{Molecules or Signal Transduction Pathways}

\subsection{Molecules}

3.1.1. AGEs. The detrimental effects of hyperglycemia can be attributed to the biochemical consequences of intracellular metabolism associated with excess glucose, including nonenzymatic glycation with formation of AGEs [1]. AGEs are heterogeneous compounds that interact with the arterial wall through receptors for AGE (RAGEs). Formation of GlyLDLs and other AGEs induces uptake of proatherogenic lipids by cultured aortic SMCs [19] and stimulation of RAGE and scavenger-receptor expression in macrophages [20]. Schmidt et al. found that the interactions between AGEs and RAGEs enhance the adhesion of monocytes to endothelial cells via stimulating the expression of nuclear factor- $\kappa \mathrm{B}$ (NF- $\kappa \mathrm{B}-$ ) dependent proinflammatory and prothrombotic molecules [21]. Consequently, the AGE/RAGE axis contributes to diabetic atherosclerosis by attracting monocytes to the vascular intima, increasing oxidative stress, inducing endothelial dysfunction, and promoting vascular wall remodeling $[22,23]$. Menini et al. have shown that d-carnosine-octylester(DCO-) attenuated AGE formation is related to its reactive carbonyl species- (RCS-) quenching activity [24]. Moreover, they also revealed that DCO treatment attenuated lesion size, necrotic area, and apoptotic cells in diabetic ApoE-null mice. These protection effects were more effectively achieved by early treatment $(60 \mathrm{mg} / \mathrm{kg}$ body weight, from weeks 1 to 11 , DCO early) than by late treatment $(60 \mathrm{mg} / \mathrm{kg}$ body weight, from weeks 9 to 19, DCO late) [25]. Zhu et al. [26] demonstrated that immunized diabetic $\mathrm{ApoE}^{-/-}$and low-density lipoprotein (LDL) receptor knockout (LDLR) $)^{-/-}$mice with AGE-LDL significantly reduced atherosclerosis, indicating that vaccination with AGE-LDL may offer a novel approach for the treatment of atherosclerosis in patients with diabetes. Inhibition of RAGE using murine-soluble RAGE (sRAGE) attenuates atherosclerotic lesions in STZinduced diabetic $\mathrm{ApoE}^{-/-}$mice and $\mathrm{ApoE}^{-/} / \mathrm{db} / \mathrm{db}$ mice [27]. These findings further supported the roles of AGE and RAGE in the macrovascular complications of diabetes, and blockade of RAGE may be a potential therapeutic strategy in diabetic atherosclerosis.

3.1.2. ACSL1. A recent study showed that monocytes and macrophages expressed increased levels of ACSL1 (an enzyme that catalyzes the thioesterification of fatty acids) in both diabetic mouse models and human subjects [6]. ACSL1 is markedly induced by the TLR4 ligand lipopolysaccharide (LPS) in isolated macrophages, suggesting that ACSL1 may 
TABLE 1: MicroRNA involved in diabetic atherosclerosis.

\begin{tabular}{|c|c|c|c|c|}
\hline miR type & Animal model & Mechanism & Target gene & Reference \\
\hline miR33 & STZ-induced diabetic Ldlr-/- mice & Increased macrophages and lipid content & ABCA1 & [37] \\
\hline $\operatorname{miR} 125 b$ & Type 2 diabetic $\mathrm{db} / \mathrm{db}$ mice & Increased inflammatory gene expression & SUV39H1 & [38] \\
\hline $\operatorname{miR} 200$ & Type 2 diabetic $\mathrm{db} / \mathrm{db}$ mice & Increased inflammatory gene expression & Zeb1 & [39] \\
\hline $\operatorname{miR} 504$ & Type 2 diabetic $\mathrm{db} / \mathrm{db}$ mice & Vascular smooth muscle phenotype change & Grb10 & {$[40]$} \\
\hline $\operatorname{miR} 138$ & Type 2 diabetic $\mathrm{db} / \mathrm{db}$ mice & Vascular smooth muscle phenotype change & SIRT1 & [41] \\
\hline
\end{tabular}

ABCA1: ATP-binding cassette transporter A1; SIRT1: silent information regulator 1.

be a downstream effector of TLR4 cascade in macrophages [28]. Myeloid-specific ACSL1 deficiency results in a specific reduction in 20:4-COA levels and completely prevents the increased release of prostaglandin E2 (PGE2) and increased inflammatory phenotype in monocytes and macrophages from diabetic mice, suggesting that the inflammatory phenotype is associated with increased expression of ACSL1. In addition, increased chemokine (C-C motif) ligand 2 (CCL2) secretion from macrophages in diabetic mice is completely prevented by ACSL1 deficiency, supporting that monocyte recruitment is reduced by ACSL1 deficiency [6]. Kanter et al. [29] demonstrated that ACSL1 could directly influence ATP-binding cassette transporter A1 (ABCA1) levels and cholesterol efflux in mouse macrophages. Mouse macrophages deficient in ACSL1 displayed increased ABCA1 levels and increased apolipoprotein A-I-dependent cholesterol efflux in the presence of unsaturated fatty acids compared with those of wild-type mouse macrophages. Conversely, overexpression of ACS1 led to reduced ABCA1 levels and reduced cholesterol efflux in the presence of unsaturated fatty acids. Taken together, the reduced levels of cholesterol efflux and expression of ABCA1 in mouse macrophages in the context of diabetes and elevated fatty load were partly mediated by ACSL1.

3.1.3. Paraoxonase (PON1). In the state of high oxidative stress, such as STZ-induced diabetes, serum PON1 and arylesterase activities were reduced [30, 31]. Decreased serum PON activity is related to glycation and glycol oxidation of high-density lipoprotein (HDL) in the hyperglycemic state, thus leading to impairment of HDL activity, such as protection of LDL from oxidation, cholesterol efflux from cells, and inhibition of monocyte migration to endothelial cells $[32,33]$. Taş et al. have demonstrated that vitamin B6 supplementation enhances serum PON1 and arylesterase activities, which could be related to the potential direct effects of this vitamin on the enzyme and/or to its ability to reduce oxidative stress [34]. These results suggested that protection of PON1 from inactivation may be a potential therapeutic approach for the treatment of diabetic atherosclerosis.

3.1.4. Insulinotropic Polypeptide (GIP). As illustrated previously, high glucose accelerates atherosclerosis and foam cell formation. GIP potently stimulates insulin release from the pancreas under conditions of normal glucose tolerance. However, under diabetic conditions, the activity of GIP is reduced [35]. Thus, GIP is thought to be involved in diabetic atherosclerosis. According to Nogi et al. [36], chronic administration of GIP in vivo attenuates macrophagedriven atherosclerotic lesions in STZ-induced diabetic $\mathrm{ApoE}^{-/-}$mice, although this effect is abolished by cofusion with a GIPR antagonist, $\left[\mathrm{Pro}^{3}\right.$ ]GIP. GIP infusion attenuates foam cell formation in both diabetic $\mathrm{ApoE}^{-1-}$ mice and $\mathrm{db} /$ $\mathrm{db}$ mice. In vitro treatment with GIP $(1 \mathrm{nM})$ reduces foam cell formation by $15 \%$ in macrophages from diabetic $\mathrm{ApoE}^{-/-}$mice.

3.1.5. MicroRNA (miRNA). miRNA is a class of conserved 19-25-nucleotide noncoding RNAs that regulate gene expression posttranscriptionally. Recently, researchers have demonstrated that miRNAs play important roles in diabetes and related complications (Table 1). According to a study by Distel et al., treatment of STZ-induced diabetic $\mathrm{LDLR}^{-/}$ mice with anti-miR-33 decreases plaque macrophage content and inflammatory gene expression in diabetic $\mathrm{LDLR}^{-1-}$ mice, accompanied by upregulation of $\mathrm{ABCA} 1$, which mediates cholesterol efflux from macrophages in the plaque [37]. Villeneuve et al. [38] first demonstrated the role of $m i R-125 b$ in vascular complications of diabetes. They verified that $m i R$ $125 b$, which targets SUV39H1, led to increased levels of inflammatory genes, such as $I L-6$ and MCP-1. miR-125b mimic significantly increased monocyte binding to smooth muscle cells in $\mathrm{db} / \mathrm{db}$ mice. According to a study by Reddy et al. [39], the expression levels of $m i R-200 b$ and $m i R-200 c$ were increased, whereas Zeb1 protein levels were decreased in VSMCs and aortas from $\mathrm{db} / \mathrm{db}$ mice relative to those in control db/+mice. Transfection with miR-200 mimic downregulated Zeb1, upregulated the inflammatory genes $C O X-2$ and $M C P-1$, and promoted monocyte binding in $\mathrm{db} /+$ VSMCs. Both miR mimics and Zeb1 siRNA increased the proinflammatory response in $\mathrm{db} / \mathrm{db}$ VSMCs. In contrast, miR-200 inhibitors reversed the enhanced monocyte binding of $\mathrm{db} / \mathrm{db}$ VSMCs. Moreover, miR-504 significantly upregulated in $\mathrm{db} / \mathrm{db}$ VSMCs compared with that in $\mathrm{db} /+\mathrm{VSMCs}$ [40]. miR-504 may enhance extracellular regulated protein kinase 1/2 (ERK1/2) activation by targeting Grb10 and thereby contribute to changes in the VSMC phenotype. According to $\mathrm{Xu}$ et al. [41], higher $m i R-138$ levels and reduced expression of silent information regulator 1 (SIRT1) were observed in SMCs isolated from $\mathrm{db} / \mathrm{db}$ mice. Additionally, miR-138 promotes smooth muscle cell proliferation and migration in $\mathrm{db} / \mathrm{db}$ mice through downregulation of SIRT1, whereas transfection with miR-138 inhibitor reverses these effects.

3.1.6. Tribbles Homolog 3 (TRIB3). The expression of TRIB3, a protein made up of 358 amino acids, is increased in patients 


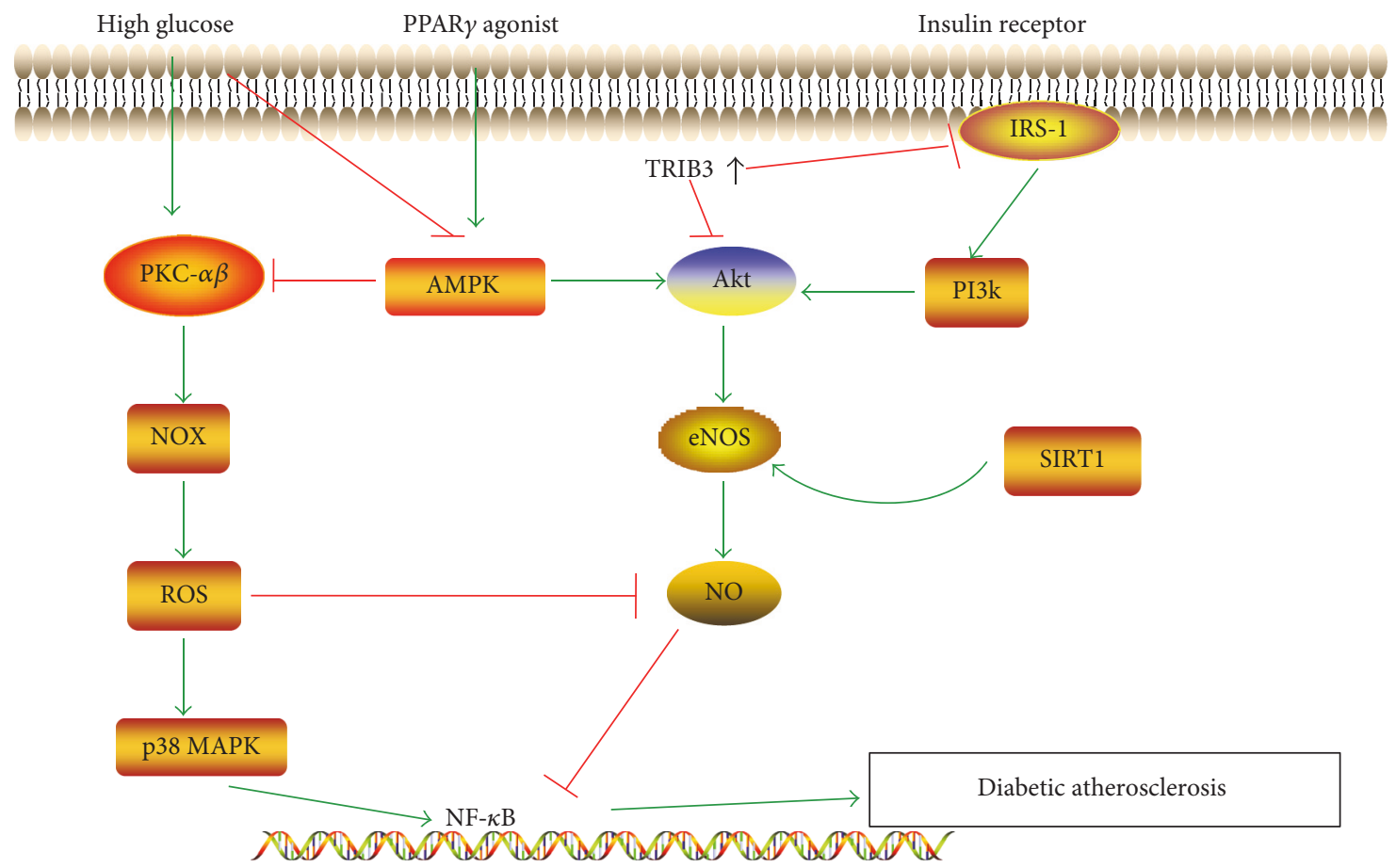

FIgURE 1: The NF- $\kappa$ B signalling pathway is involved in the diabetic atherosclerosis. Decreased NO produced by eNOS is associated with diabetic atherosclerosis. PI3K and AMPK are upstream of Akt and eNOS. Under hyperglycemic conditions, PKC activates NOX, the major source of reactive ROS production, leading to the activation of p38 MAPK and NF- $\kappa$ B and decrease in NO bioavailability. AMPK suppression in the context of high glucose contributes to the downregulation of the Akt/NO cascade. Increased levels of TRIB3 inhibit the phosphorylation of Akt directly or by reducing activation of PI3K/Akt. SIRT1 stimulates NO production by deacetylating eNOS at lysine residues or by upregulating AMPK. PPAR $\gamma$ agonists activate AMPK, which in turn increases the bioactivity of eNOS and prevents PKC-activated NOX caused by high glucose. PKC: protein kinase; NOX: NADPH oxidase; TRIB3: Tribbles homolog 3; ROS: reactive oxygen species; p38 MAPK: p38 mitogen-activated protein kinase; PI3K: phosphatidylinositol 3-kinase; AMPK: AMP-activated protein kinase; eNOS: endothelial NO synthase; IRS-1: insulin receptor substrate 1; SIRT1: silent information regulator 1; PPAR $\gamma$ : peroxisome proliferator-activated receptor $\gamma$.

and animals with type 2 diabetes [42]. Endoplasmic reticulum stress, an important feature of diabetes, has also been shown to increase TRIB3 expression, thus promoting cell death in response to endoplasmic reticulum stress [43].TRIB3 impairs insulin metabolic signalling by increasing serine phosphorylation of insulin receptor substrate 1 (IRS-1), reducing activation of phosphatidylinositol 3-kinase (PI3K)/Akt [44], or directly inhibiting the phosphorylation of Akt $[45,46]$.

Several mechanisms are involved in TRIB3-dependent promotion of atherosclerotic lesions. TRIB3 impairs IRS-1/ Akt signalling in endothelial cells mediated by insulin [47], leading to reduced endothelial nitric oxide synthase (eNOS) and NO bioavailability [46], which is associated with endothelial dysfunction and increased leukocyte adhesion to endothelial cells, important steps for atherosclerotic lesion formation (Figure 1) [9]. In addition, TRIB3 is involved in lipid metabolism and macrophage apoptosis, an important feature for vulnerable plaques [48, 49]. According to a study by Wang et al. [49], silencing of TRIB3 in STZ plus diet-induced diabetic $\mathrm{ApoE}^{-/-} / \mathrm{LDLR}^{-/}$mice significantly decreases insulin resistance and blood glucose and reduces the numbers of apoptotic cells and macrophages in atherosclerotic lesions. Consequently, silencing of TRIB3 attenuates the atherosclerosis burden and promotes plaque stability in diabetic mice. Thus, TRIB3 is a promising target for the treatment of diabetic atherosclerosis.

\subsection{Signalling Pathways}

3.2.1. The Janus Kinase (JAK)/Signal Transducers and Activators of Transcription (STAT) Cascade. JAK/STAT is an essential intracellular pathway that regulates leukocyte recruitment, foam cell formation, and proliferation and migration of VSMCs, which are important features in atherosclerosis [50-52]. STAT isoforms have been found in the atherosclerotic lesions in both humans and animal models [53, 54]. STAT signalling cascade contributes to the macrophage apoptosis in advanced atherosclerotic plaque [55]. Inhibition of JAK2, STAT1, and STAT3 reduces lesion size and neointimal hyperplasia [56, 57]. Moreover, JAK/STAT is also a pivotal inflammatory mechanism through which hyperglycemia contributes to the pathogenesis of diabetes mellitus and its vascular complications [58-60]. High glucose stimulates endothelial IL-6 secretion via redox-dependent mechanisms, which may consequently induce STAT3 activation and ICAM-1 expression; the specific STAT3 inhibitor SI-201 $(20 \mu \mathrm{M})$ suppresses high glucose-induced ICAM expression 
in cultured human umbilical vein endothelial cells (HUVECs) [61]. The suppressor of cytokine signalling (SOCS) family regulates JAK/STAT signalling through STAT binding, kinase inhibition, targeting for proteasomal degradation, or direct suppression of JAK tyrosine kinase activity $[62,63]$. According to a report by Recio et al. [64], SOCS1 peptide inhibits STAT1/STAT3 activation and target gene expression in VSMCs and macrophages and blocks the migration and adhesion of macrophages in vitro. Their results showed that intraperitoneal injection of SOCS1 into STZ-induced diabetic $\mathrm{ApoE}^{-/-}$mice (ages 8 and 22 weeks) for 6-10 weeks suppressed STAT1/STAT3 activation in atherosclerotic plaques and significantly attenuated lesion size for both early and advanced lesions. The accumulation of lipids, macrophages, and $\mathrm{T}$ lymphocytes was decreased following treatment with SOCS1 peptide, whereas collagen and smooth muscle cell content were significantly increased. Thus, the SOCS/JAK/STAT cascade was a key molecular mechanism through which diabetes promoted atherosclerotic plaque formation, and SOCS1 endogenous protein may be a feasible target for modulating inflammation-related complications of diabetes mellitus. Approaches to supplement SOC1 or mimic native SOCS1 function may have therapeutic effects on accelerated atherosclerosis in diabetes.

3.2.2. The eNOS/NO Pathway. NO produced by eNOS is an important vasodilator that possesses multiple antiatherosclerotic properties. eNOS-derived NO has been shown to inhibit platelet aggregation, block vascular inflammation by inhibiting the activation of NF- $\kappa \mathrm{B}$ [65], and suppress VSMC proliferation. As illustrated previously, decreased bioactivity of NO is associated with exposure of endothelial cells to high-glucose concentration [9]. High-glucose levels block endothelial injury repair by circulating endothelial progenitor cells (EPCs) through decreasing eNOS/NO bioavailability $[9,66,67]$. According to a study by Sun et al. [68], the Akt kinase inhibitor (GSK690693) inhibited Akt and eNOS phosphorylation, suggesting that Akt may be necessary to activate eNOS. The PI3K inhibitor LY-29402 inhibits vaspin-induced eNOS and Akt phosphorylation, suggesting that PI3K acts upstream of Akt activation and eNOS. Additionally, vaspin induces endothelial protective effects via the PI3K/Akt/eNOS pathway. Ouchi et al. [69] showed that adiponectin-induced Akt phosphorylation, eNOS phosphorylation, and cell migration and differentiation in HUVECs were abolished when the cells were transduced with a dominant-negative form of AMP-activated protein kinase (AMPK). However, AMPK phosphorylation was not affected by dominantnegative transduction in HUVECs, suggesting that AMPK acts upstream of Akt in the Akt/eNOS/NO pathway to regulate endothelial function under conditions of hyperglycemia. SIRT1 is a class III histone deacetylase that has been shown to stimulate NO production by deacetylating eNOS at lysine residues [70] or by mediating the activation of AMPK [71]. Yang et al. [70] found that SIRT1 had a positive role in improving the expression of eNOS impaired by high glucose, and the low level of NO in endothelial cells cultured in the presence of high glucose may be partly related to the decreased expression of SIRT1 (Figure 1).
3.2.3. The Mitogen-Activated Protein Kinase (MAPK) Pathway. The MAPK pathway, including p38 MAPK, ERK, and c-Jun N-terminal kinase (JNK) branches, is involved in vascular inflammation. ERKs are typically initiated by Ras, which can be stimulated by inflammatory cytokines from high-glucose injured endothelial cells, leading to the proliferation of SMCs [72-75]. p38 MAPK activation is associated with diabetes and its complications, and the detrimental effects of high glucose can be blocked by coincubation with a p38 MAPK inhibitor [67]. Moreover, p38 MAPK has been shown to be involved in diabetic atherosclerosis. Hyperglycemic culture conditions accelerate the onset of EPC senescence, leading to impairment of endothelial repair, potentially through the activity of the p38 MAPK pathway [76]. Microparticles (MPs), which are submicron membrane vesicles $(0.1-1 \mu \mathrm{m})$ shed from the plasma membrane of activated or apoptotic cells, are significantly increased in the presence of high-glucose levels. According to a study by Jansen et al. [77], p38 MAPK is activated to phosphop38MAPK within $30 \mathrm{~min}$ when human coronary endothelial cells (HCAECs) are treated with "injured" EMP (iEMP, MPs derived from glucose-treated HCAECs), whereas there is no change following treatment with normal endothelial cellderived MPs (EMPs). iEMP-induced expression of ICAM-1 and VCAM-1 and monocyte adhesion to HCAECs were significantly reduced by pretreatment of HCAECs with the p38MAPK inhibitor SB-203580 $(1 \mu \mathrm{m})$. Consequently, these results showed that p38MAPK was involved in iEMPinduced endothelial dysfunction and monocyte adhesion. Further studies have shown that iEMP increases ROS production through NADPH oxidase (NOX) activation in endothelial cells, thus leading to activation of p38 MAPK. The p38 MAPK signalling pathway in diabetic atherosclerosis is illustrated in Figure 1.

3.2.4. The Protein Kinase (PKC) Pathway. High concentrations of glucose and nonesterified fatty acids result in activation of PKC. Active PKC is involved in vascular inflammation through the generation of proinflammatory cytokines and chemokines. PKC activates NOX, the major source of ROS production in high-glucose stress, thus leading to the activation of signalling pathways such as ERK, p38 MAPK, and NF- $\kappa \mathrm{B}$ and decreased NO bioavailability (Figure 1) $[78,79]$. ROS not only activate p38 MAPK but also act as an agonist to activate the nucleotide-binding domain-like receptor 3 (NLRP3) inflammasome, further disrupting endothelial function. These effects could be prevented by AMPK [80]. Durpès et al. [78] showed that PKC $\beta$ decreases the expression of IL-18-binding protein (IL-18BP), a molecule involved in a negative feedback mechanism in response to elevated IL18 production, thus enhancing the production of cytokines and cellular adhesion molecules, which promote atherosclerotic plaque formation and instability in STZ-induced diabetic $\mathrm{ApoE}^{-1-}$ mice. Kong et al. [81] found that activated plasma membrane-bound $\mathrm{PKC} \beta$ is elevated in the aortas of low-dose STZ-induced hyperglycemic $\mathrm{ApoE}^{-/-}$mice and that pharmacological inhibition of $\mathrm{PKC} \beta$ attenuates atherosclerotic lesions in hyperglycemic $\mathrm{ApoE}^{-/-}$mice. Deficiency of PKC $\beta$ blocks the upregulation of Egr-1, ERK1/2, and 
JNK and results in diminished lesional macrophages and CD11c-expressing cells in diabetic $\mathrm{ApoE}^{-/-}$mice. In vitro, inhibitors of PKC $\beta$ and ERK1/2 significantly decrease high glucose-induced expression of CD11c, CCL2, and IL-1 $\beta$ in U937 macrophages. These studies suggest that selective PKC $\beta$ inhibitors may have potential therapeutic effects in diabetes-associated atherosclerosis.

\subsubsection{The Peroxisome Proliferator-Activated Receptor} $(P P A R) \gamma$ Signalling Pathway. Accumulating evidence has shown that PPAR $\gamma$ has protective effects in both diabetes and atherosclerosis. In a combined diabetes/atherosclerosis mouse model, PPAR $\gamma$ agonists were found to exert antiatherogenic effects independent of a reduction in insulin resistance and plasma glucose [82], indicating that attenuation of insulin resistance is not the only mechanism through which PPAR $\gamma$ functions as an antiatherognic agent. PPAR $\gamma$ agonists activate AMPK, which in turn increases the bioactivity of eNOS and prevents PKCactivated NOX caused by high glucose [80, 83]. Pioglitazone downregulates RAGE expression and inhibits ROS production and NF- $\kappa$ B activation via PPAR $\gamma$ activation, which may prevent the inflammatory effects of the AGE/ RAGE system in diabetes [84]. Recent studies have shown that pioglitazone attenuates platelet-derived growth factor (PDGF)-induced VSMC proliferation through AMPKdependent and -independent inhibition of mammalian target of rapamycin (mTOR)/p70S6K and ERK signalling [85]. Furthermore, PPAR $\gamma$ agonists have been reported to promote cholesterol efflux from macrophages via upregulation of ABCA1 expression $[86,87]$. The PPAR $\gamma$ signalling pathway in antiatherosclerosis under hyperglycemic conditions is illustrated in Figure 1.

3.2.6. The Nuclear Factor of Activated T Cells (NFAT) Signalling Pathway. NFAT proteins are a family of $\mathrm{Ca}^{2+} / \mathrm{cal}-$ cineurin-dependent transcription factors first characterized in Tlymphocytes as inducers of cytokine gene expression. There are four well-characterized members of the NFAT family, which function in VSMC proliferation in the context of atherosclerosis and hypertension and have roles in glucose and insulin homeostasis [88]. According to a study by Nilsson et al., in intact cerebral arteries, raising the extracellular glucose concentration from $11.5 \mathrm{mM}$ (control) to $20 \mathrm{mM}$ [HG] for 30 min significantly increases NFAT nuclear accumulation, accompanied by enhanced transcriptional activity. UTP and UDP mediate glucose-induced NFAT activation via P2Y receptors. High-glucose concentrations downregulate glycogen synthase kinase 3 (GSK) $\beta$ and JNK activity, leading to decreased export of NFATc3 from the nucleus and enhanced robust NFATc3 nuclear accumulation, representing another mechanism for glucose-induced NFAT activation [89]. NFATc3 is activated by hyperglycemia, thereby inducing the expression of osteopontin (OPN), a cytokine that promotes diabetic atherosclerosis [90]. Zetterquist et al. demonstrated a link between NFAT activation and diabetic atherosclerosis using STZ-induced diabetic ApoE ${ }^{-1-}$ mice. In vivo treatment with the NFAT inhibitor A285222 $(0.29 \mathrm{mg} /$ $\mathrm{kg} /$ day i.p.) for 4 weeks prevented diabetes-associated atherosclerosis lesions in the aortic arch independent of blood glucose lowering, accompanied by decreased expression of IL-6, OPN, MCP-1, and ICAM-1 and the macrophage markers CD68 and tissue factor (TF) in the aortic arch. These findings revealed that the NFAT signalling pathway may be a promising target for the treatment of diabetes-associated atherosclerosis [91].

3.2.7. The Nrf2 Signalling Pathway. Ungvari et al. demonstrated the vasoprotective role of Nrf2 in diabetes using $\mathrm{Nrf}^{-/-}$mice. They showed that the expression of Nrf2 downstream genes was significantly upregulated in diabetic $\mathrm{Nrf}^{+/+}$mice, but not in diabetic Nrf2 ${ }^{-/-}$mice [92]. Under normal conditions, Nrf2 constitutively interacts with keap1, a negative regulator, for ubiquitination and degradation in the cytosol. Under high-glucose stress, Nrf2 is released from keap 1 and translocates to the nucleus and subsequently binds to antioxidant-responsive elements (ARE); this results in increased transcription of genes such as $\mathrm{NADPH}$ : quinine oxidoreductase 1 (NQO1), heme oxygenase-1 (HO-1), superoxide dismutase (SOD), and catalase (CAT). These antioxidant enzymes decrease the levels of ROS, thus attenuating diabetic atherosclerosis (Figure 2) [93]. These results suggest that Nrf2 activators may have efficacy in the management of diabetic atherosclerosis.

\section{Herbal Medicines: Promising Therapeutic Agents for the Management of Diabetic Atherosclerosis}

4.1. Ginkgo biloba. Ginkgo biloba is a dioecious tree with a history of use in traditional Chinese medicine and has many pharmacologic effects. Ginkgo has vascular protection functions due to its antioxidant effects, free radical scavenging activity, stabilization of membranes, and inhibition of platelet-activating factor. Ginkgo biloba extract (GBE), produced from Ginkgo biloba leaves, is commonly used in dietary supplements for aliments and has shown excellent clinical effects in many cases. GBE contains terpenoids, flavonoids, alkylphenols, polyprenols, and organic acids. Terpenoids (including ginkgolides and biobalide) and flavonoids are the two major groups of active substances in Ginkgo leaves. The basic structures of ginkgolides, biobalides, and Ginkgo biloba flavonol aglycones are shown in Figures 3(a), 3(b), 3(c).

There have been several reports showing that EGB761, a standard GBE, improves glucose homeostasis, possibly because of increased plasma insulin levels, via protection of pancreatic $\beta$-cells and/or stimulation of insulin secretion. Cheng et al. reported that $\operatorname{GBE}(100,200$, and $300 \mathrm{mg} / \mathrm{kg})$ administered orally once a day for 30 days caused a significant dose- and time-dependent reduction in blood glucose levels in diabetic rats. In their study, GBE increased the activities of SOD, CAT, and glutathione peroxidase (GSH-Px) in diabetic rats and resulted in protection of pancreatic $\beta$-cells [94]. In addition, several reports have shown that GBE lowers blood glucose by improving insulin resistance [95-97]. Thus, GBE may attenuate atherosclerosis in the context of diabetes. According to a study by Lim et al. [98], neointimal formation 


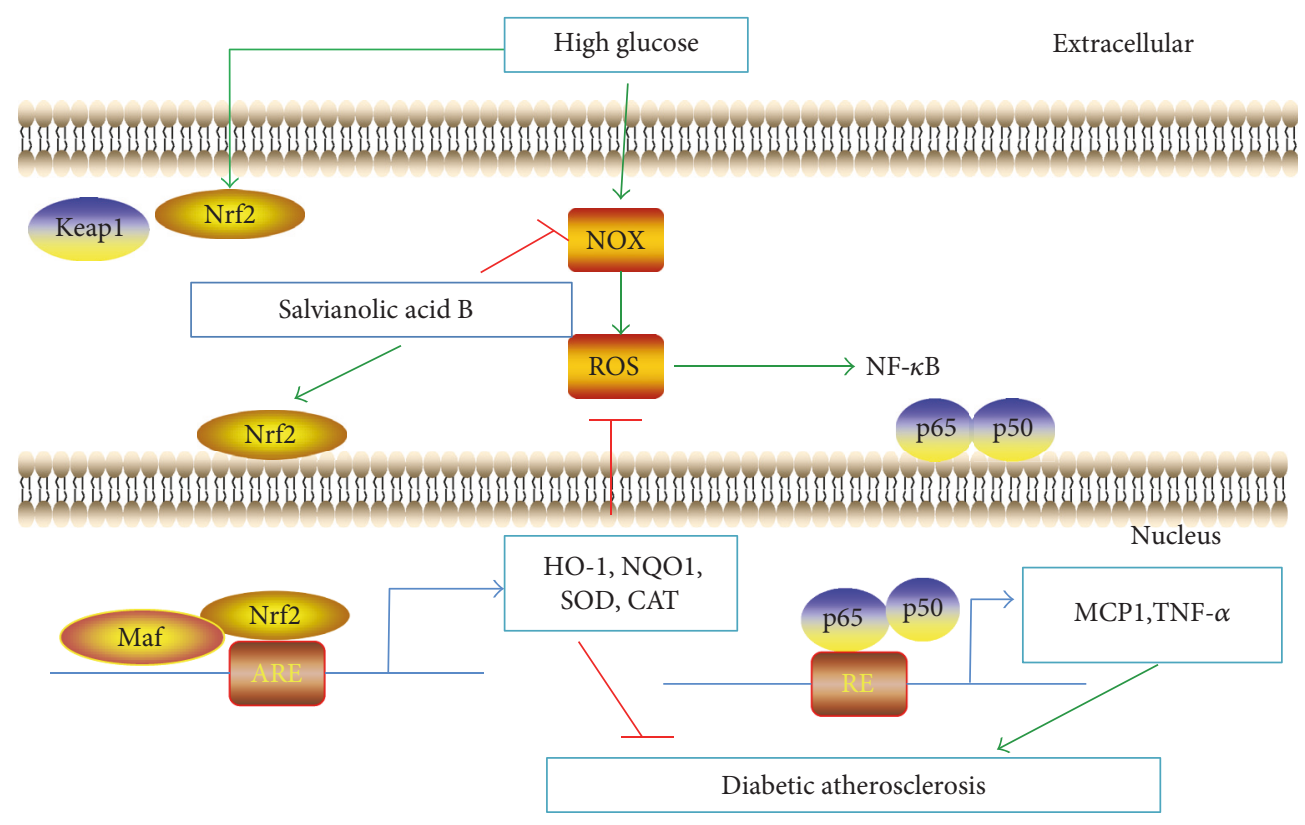

FIgURE 2: Salvianolic acid B protects against diabetic atherosclerosis via the Nrf2 signalling pathway. Under normal conditions, Nrf2 constitutively binds to keap1, a negative regulator in the cytosol. Under high-glucose stress, Nrf2 is released from keap1 and translocates to the nucleus, enhancing the transcriptional activity of NADPH: quinine oxidoreductase 1 (NQO1), heme oxygenase-1 (HO-1), superoxide dismutase (SOD), and catalase (CAT). These antioxidant enzymes decrease the levels of ROS. Salvianolic acid B is capable of upregulating Nrf2 activity or inhibiting NOX generation directly. ARE: antioxidant-responsive element; HO-1: heme oxygenase-1; NQO1: quinine oxidoreductase 1; SOD: superoxide dismutase; CAT: catalase.

in balloon-injured carotid arteries is significantly reduced when insulin-resistant rats are treated with EGb761 (100 or $200 \mathrm{mg} / \mathrm{kg} / \mathrm{day}$ ) for 6 weeks, resulting in reduced proliferation and migration of VSMCs. EGb761 $(50-200 \mu \mathrm{g} / \mathrm{mL})$ decreases the proliferation of rat aortic SMCs in a concentration-dependent manner in vitro. In addition, EGb761 at both 100 and $200 \mu \mathrm{g} / \mathrm{mL}$ suppresses the expression of ICAM and VCAM in HUVECs. Zhao et al. [99] found that GBE improves SOD activity and reduces the rate of apoptosis of EPCs within the peripheral blood of diabetic patients in a dose-dependent manner. According to Tsai et al. [100], GBE inhibits high glucose-induced ROS generation, adhesion molecule expression, and monocyte adhesiveness in human aortic endothelial cells (HAECs) via the Akt/eNOS and p38 MAPK pathways. Another study showed that Ginkgolide A at 10, 15, and $20 \mu \mathrm{M}$ inhibits high glucose-induced IL-4, IL-6, and IL-3 expression in HUVECs. Ginkgolide A attenuates vascular inflammation by regulating the STAT3-mediated pathway [61]. According to a study by Wang et al. [101], treatment with the rutin (30 and $100 \mu \mathrm{M})$ significantly restores NO production by decreasing NOX4 mRNA and protein levels and reducing the generation of ROS in HUVECs under high-glucose conditions. Furthermore, rutin at doses of 35 and $70 \mathrm{mg} / \mathrm{kg}$ improves endothelium function by restoring impaired NO generation from glucose-triggered endothelial cells and ameliorating the endothelial contraction and relaxation response in thoracic aortas of rats with a high-glucose diet. The potential mechanism for GBE in the treatment of diabetic atherosclerosis is shown in Figure 4.
4.2. Tetramethylpyrazine (TMP). TMP is a biologically active compound isolated from rhizomes of Ligusticum chuanxiong, a traditional Chinese medicine (Figure 3(d)). Several studies have shown that TMP exerts antiatherosclerosis effects through promotion of endothelial protection, inhibition of VSMC proliferation, reduction of oxidative stress, and suppression of inflammation and apoptosis. The link between TMP and NO generation has been verified by several researchers. For example, Lv et al. [102] demonstrated that TMP pretreatment in vivo enhances Akt and eNOS phosphorylation. Additionally, Xu et al. reported that Qiong Huo Yi Hao (QHYH), which consists of several herbals based on the "clearing heat and detoxifying" principle of traditional Chinese Medicine, is a potent antioxidant acting to scavenge superoxide anions in endothelial cells treated with high concentrations of glucose [103]. TMP, an active compound in $\mathrm{QHYH}$, has been shown to be the strongest component of QHYH in the prevention of ROS production, functioning to block Akt/eNOS phosphorylation and reduce NO generation in endothelial cells treated with high concentrations of glucose [104]. Xu et al. further demonstrated that TMP ameliorates high glucose-induced endothelial dysfunction by increasing mitochondrial biogenesis through reversing high glucose-induced suppression of SIRTI1 [105]. These findings provide evidence for the endothelial protection function of TMP in the context of hyperglycemia. Studies have shown that TMP can suppress the proliferation of VSMCs [106], and the ERK and p38MAPK pathways may be involved in this process [107]. Additionally, TMP can block LPS-induced IL-8 overexpression in HUVECs at both protein and mRNA levels, 


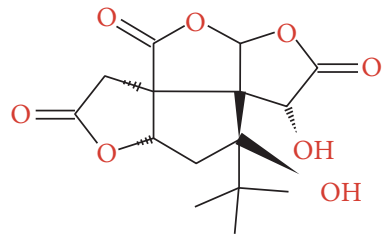

(a) Bilobalide<smiles>[R]c1cc(-c2oc3cc(O)cc(O)c3c(=O)c2O)ccc1O</smiles>

(c) Ginkgo biloba flavonol aglycones

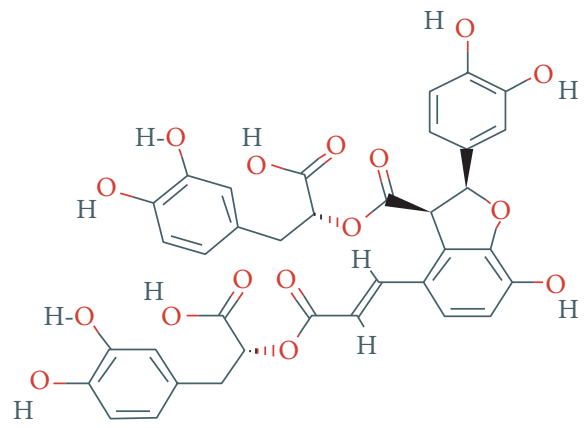

(e) Salvianolic acid B

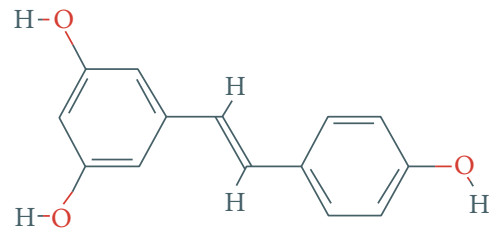

(g) Resveratrol

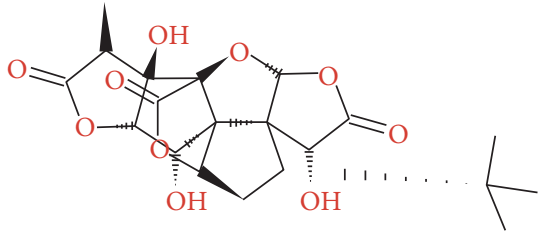

(b) Ginkgolide<smiles>Cc1nc(C)c(C)nc1C</smiles>

(d) Tetramethylpyrazine

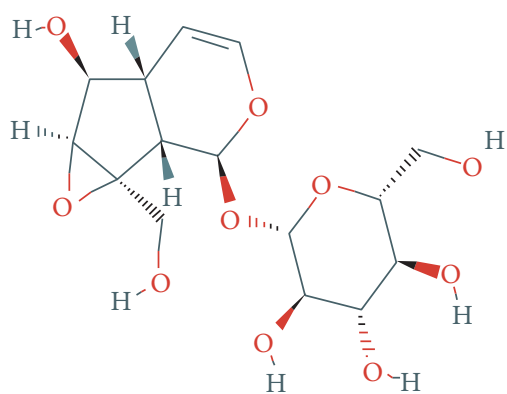

(f) Catalpol<smiles>COc1cc(/C=C/C(=O)CC(=O)/C=C/c2ccc(O)c(OC)c2)ccc1O</smiles>

(h) Curcumin

Figure 3: Molecular structure of the compounds described in this review.

which could be attributed to inhibition of the ERK and p38MAPK pathways and the inactivation of NF- $\kappa B$ [108]. The antiapoptotic function of TMP can be attributed to the inhibition of JAK/STAT signal transduction [109].

Importantly, Lee et al. [110] investigated the effects of TMP on lipid peroxidation in STZ-induced diabetic mice. The results showed that TMP dose dependently inhibited glucose concentrations, blood urea nitrogen elevation, and the degree of lipoperoxidation. Thus, TMP may be an effective agent for the treatment of diabetes and related vascular complication. The mechanisms through which TMP protects against diabetes are shown in Figure 5.

4.3. Danggui. Danggui-Buxue-Tang (DBT) is a well-known traditional formula. Zhang et al. [111] found that oral administration of DBT (3 or $6 \mathrm{~g} / \mathrm{kg} /$ day for 4 weeks) decreased the concentrations of c-reactive protein and tumour necrosis factor- $\alpha$ and resulted in higher survival rates and lower body weight loss in diabetic GK rats; the diabetic atherosclerosis rats were induced by NO inhibition (I-NAME in drinking water, $1 \mathrm{mg} / \mathrm{mL}$ ) plus a high-fat diet. They also investigated the effects of DBT on blood lipids and the expression of genes related to foam cell formation during the early stage of atherosclerosis in diabetic GK rats. The results demonstrated that DBT could regulate blood lipids and inhibit the expression of $M C P, I C A M-1$, and CD36 genes in the aorta [112]. Galgeun-dang-gwi-tang (GGDGT), a Korean herbal medicine, has traditionally been prescribed for the treatment of diabetes. In a study by Lee et al. [113], lipid metabolism and insulin resistance were shown to be improved by GGDGT in $\mathrm{ApoE}^{-1-}$ mice fed with a Western diet. Immunohistochemical staining showed that GGDGT suppressed ICAM expression, whereas the expression of eNOS and IRS-1 was restored by GGDGT in the thoracic aorta and skeletal muscle. GGDGT attenuates endothelial dysfunction via improvement of the NO-cylic guanosine monophosphate signalling pathway and promotes insulin sensitivity in diabetic atherosclerosis. 


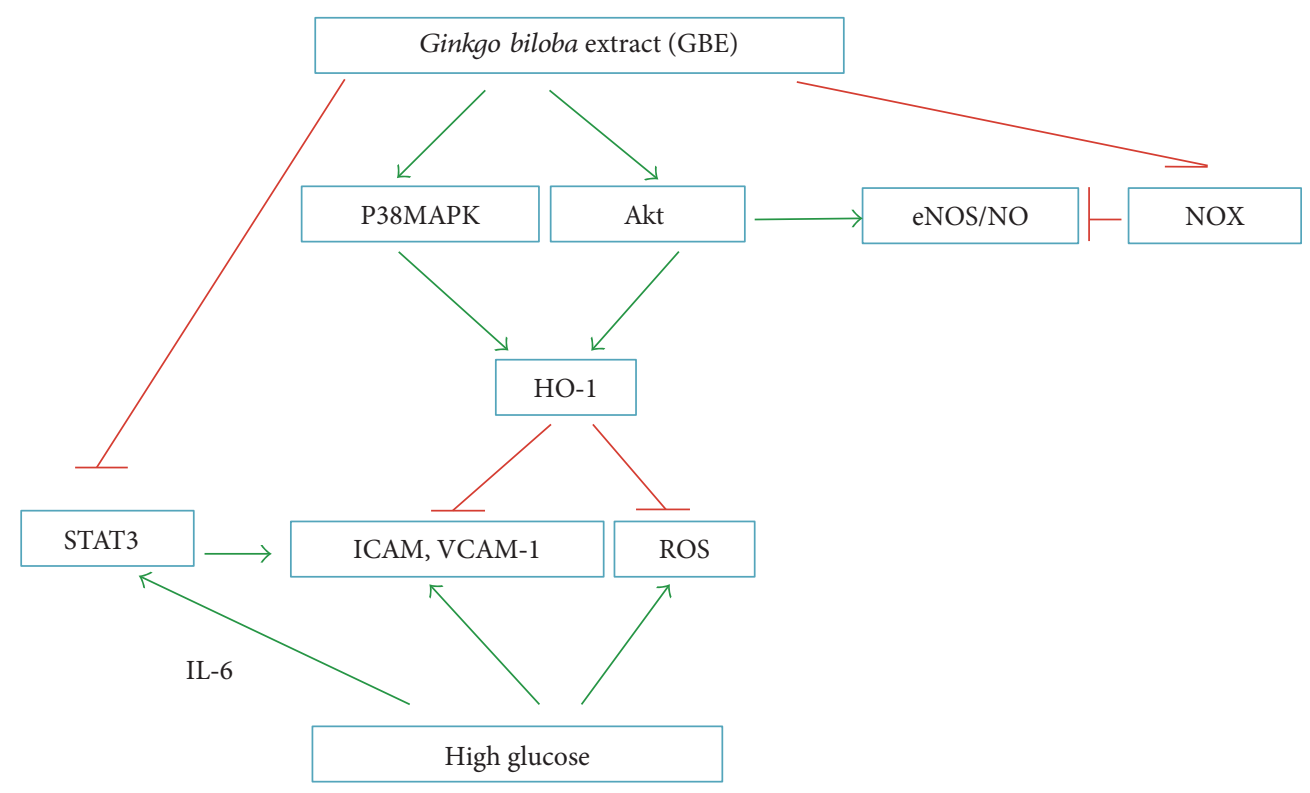

FIGURE 4: Mechanism for GBE antiatherosclerosis under diabetic conditions. STAT: signal transducer and activator of transcription; ICAM: intercellular cell adhesion molecule-1; VCAM-1: vascular cell adhesion molecule 1.

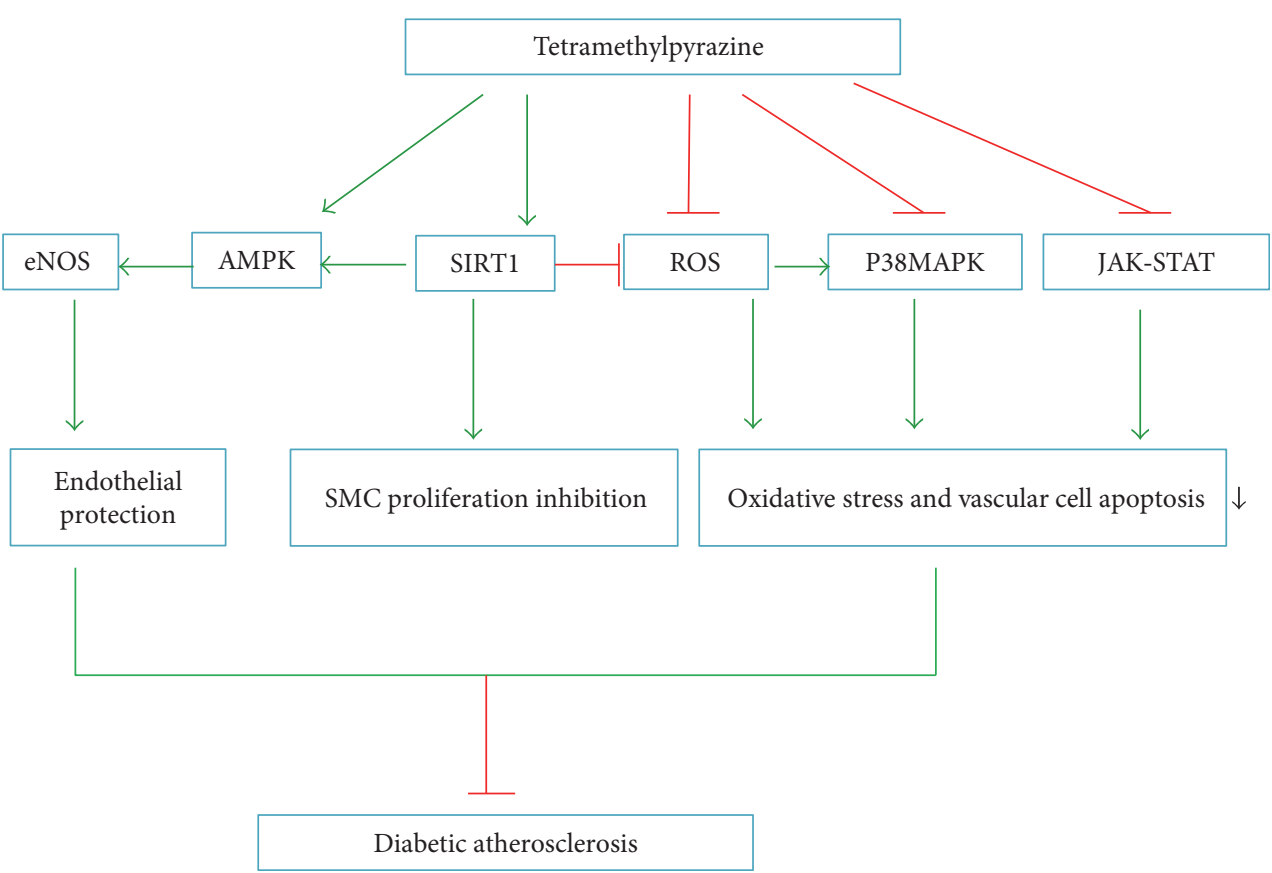

FIgURE 5: Mechanism through which tetramethylpyrazine protects against diabetic atherosclerosis.

4.4. Salvia miltiorrhiza (Danshen) and Salvianolic Acid. Salvia miltiorrhiza (Danshen), a traditional Chinese herbal medicine, is commonly used for the prevention and treatment of cardiovascular disease. Salvianolic acid B is the most abundant water-soluble compound extracted from Danshen (Figure 3(e)). Inhibition of inflammation, improvement of antioxidative effects, regulation of leukocyte endothelial adhesion, and modulation of $\mathrm{NO}$ production in endothelial cells are involved in the cardiovascular protection mechanism for Danshen and its bioactive compounds [114, 115]. Danshen extract and purified salvianolic acid B exert anti-inflammatory effects by inhibiting iNOS expression and NO production induced by LPS in RAW267.4 macrophages by inducing Nrf2-mediated HO-1 expression [114, 116]. Lee et al. [117] also demonstrated that salvianolic acid $\mathrm{B}$ inhibits platelet-derived growth factor-induced neointimal hyperplasia in arteries through induction of Nrf2-dependent $\mathrm{HO}-1$. In addition, salvianolic acid $\mathrm{B}$ increases $\mathrm{NO}$ 


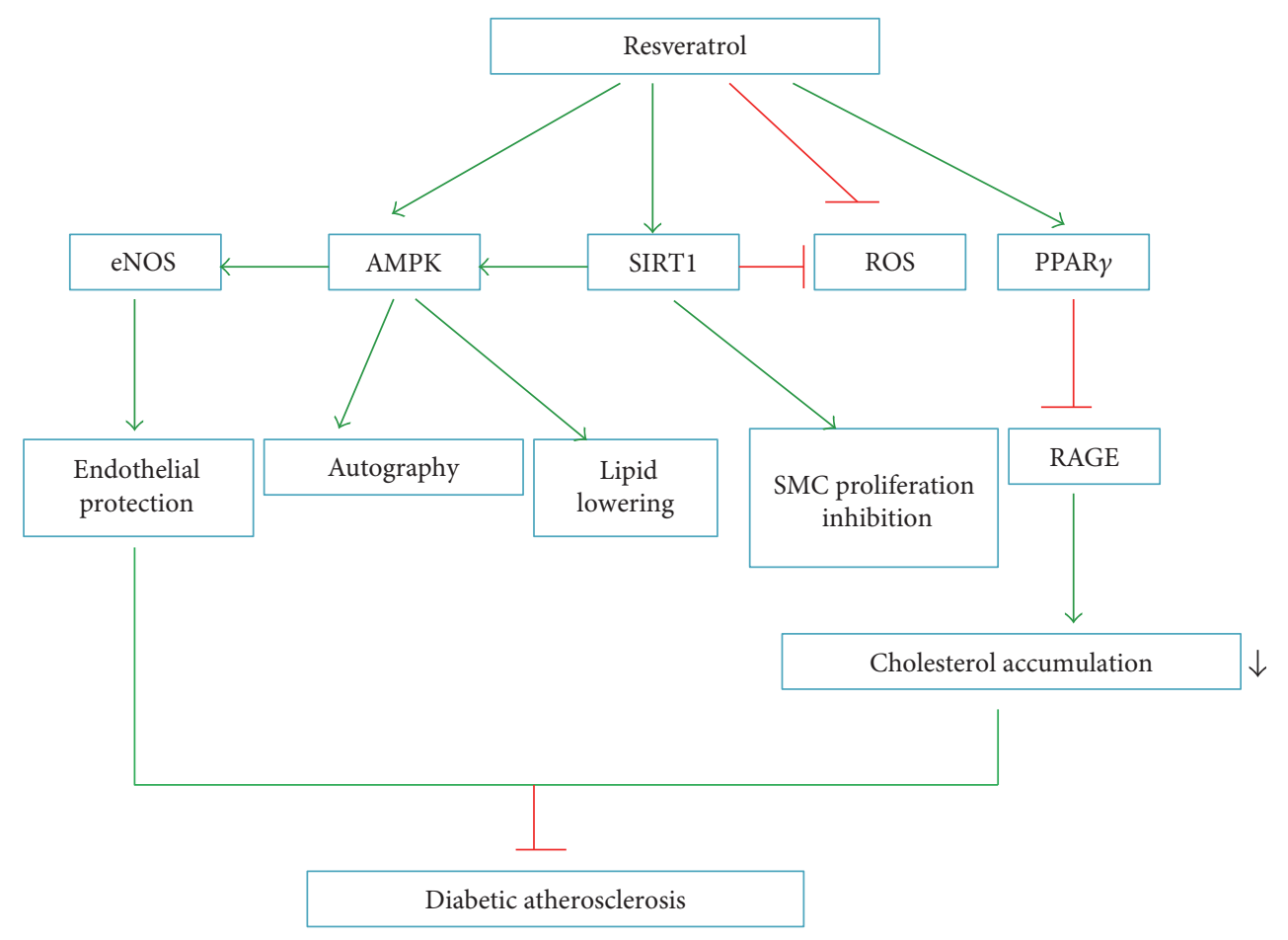

Figure 6: Antiatherosclerotic mechanism of resveratrol under diabetic conditions. RAGE: advanced glycosylation end product receptor.

production in the endothelium of isolated mouse aortas via inhibition of arginase activity [114]. According to Raoufi et al., administration of salvianolic acid B at doses of 20 or $40 \mathrm{mg} / \mathrm{kg} /$ day (i.p.) for 3 weeks significantly decreases serum glucose and improves oral glucose tolerance test (OGTT) in STZ-induced diabetic rats via attenuation of oxidative stress and apoptosis and augmentation of the antioxidant system [118]. The vascular endothelial protective function of Salvia miltiorrhiza and salvianolic acid B under high-glucose conditions has been verified both in vitro and in vivo. According to Qian et al. [119], Salvia miltiorrhiza $(10 \mu \mathrm{g} / \mathrm{mL})$ significantly decreases vascular endothelial ROS formation in human microvascular endothelial cells exposed to $30 \mathrm{mM}$ glucose. Ren et al. [120] demonstrated that salvianolic acid B significantly restores eNOS in STZ-induced diabetic rats and decreases the levels of NOX and endothelial cell apoptosis. The mechanism through which salvianolic acid B protects against diabetic atherosclerosis is shown in Figure 2.

4.5. Catalpol. Catalpol is the most abundant bioactive component in the roots of Rehmannia glutinosa (Figure 3(f)). Catalpol ameliorates plasma glucose in STZ-induced diabetic rats [121], and total cholesterol, triglycerides, and LDL cholesterol are reduced, whereas HDL cholesterol is elevated when the rats fed with high-cholesterol chow are treated with catalpol [122]. Additionally, atherosclerotic lesions and inflammatory markers are markedly reduced in the catalpol group, and catalpol attenuates atherosclerotic lesions and delays the progression of atherosclerosis in alloxan-induced diabetic rabbits. These protective effects are associated with regulation of glucose insulin homeostasis and inhibition of oxidative stress and inflammation [123].
4.6. Resveratrol. Resveratrol (trans-3,5,4'-trihydroxystilbene) is a natural polyphenol phytoalexin (Figure 3(g)) with various biological effects. The beneficial cardiovascular effects of this drug are attributable to its anti-inflammatory, antioxidative stress, endothelial protection, antiplatelet, and insulin-sensitizing effects [124]. Resveratrol increases NO bioavailability by regulating SIRT1, AMPK, and ROS. According to a study by Yang et al. [125], resveratrol restores the NO bioavailability impaired by high glucose in human endothelial cells in a SIRT1-dependent manner. Other studies have shown that resveratrol downregulates $\mathrm{NF}-\kappa \mathrm{B}$ induced by high glucose in smooth muscle cells and decreases the proliferation and migration of smooth muscle cells, a function similar to $m i R-138$ inhibitors, which result in upregulation of SIRT1 [41]. Zhang et al. [126] demonstrated that resveratrol prevents impairment of the effects of AGEs on macrophage lipid homeostasis partially by suppressing RAGEs via PPAR $\gamma$ activation, thus providing new insights into the protective roles of resveratrol against diabetic atherosclerosis. Furthermore, resveratrol lowers lipid levels and decreases hepatic lipid accumulation by stimulation of AMPK dependent on SIRT1 activity. These findings suggest that resveratrol may have potential therapeutic effects through regulation of dyslipidaemia-associated atherosclerosis in diabetes by targeting SIRTI/AMPK signalling $[127,128]$. The underlying antiatherosclerotic mechanisms of resveratrol in the context of diabetes are illustrated in Figure 6.

4.7. Curcumin. Curcumin (diferuloylmethane) is a constituent of turmeric (Curcuma longa) spice. Decreased serum LDL levels and increased serum HDL levels were observed after patients with atherosclerosis were administered $10 \mathrm{mg}$ 
TABLE 2: Fundamental application of herb in diabetic atherosclerosis.

\begin{tabular}{|c|c|c|c|c|}
\hline Drug & Dosage & Administration & Model & Reference \\
\hline \multicolumn{5}{|c|}{ In vitro studies } \\
\hline GBE & $100 \mu \mathrm{g} / \mathrm{mL}$ & Incubation $18 \mathrm{~h}$ & HAECs cultured in high glucose & {$[100]$} \\
\hline Ginkgolide A & $10,15,20 \mu \mathrm{M}$ & Preincubation $30 \mathrm{~min}$ & HUVECs cultured in high glucose & {$[61]$} \\
\hline Rutin & $30,100 \mu \mathrm{M}$ & Preincubation $30 \mathrm{~min}$ & HUVECs cultured in high glucose & {$[101]$} \\
\hline TMP & $10 \mu \mathrm{M}$ & Incubation $48 \mathrm{~h}$ & bEnd. 3 and HUVECs cultured in high glucose & {$[104]$} \\
\hline TMP & $30 \mu \mathrm{mol} / \mathrm{L}$ & Incubation $48 \mathrm{~h}$ & bEnd. 3 and HUVECs cultured in high glucose & {$[105]$} \\
\hline Salvia miltiorrhiza & $10 \mu \mathrm{g} / \mathrm{mL}$ & Incubation $48 \mathrm{~h}$ & HMECs cultured in high glucose & [119] \\
\hline Resveratrol & $1 \mu \mathrm{mol} / \mathrm{L}$ & Preincubation $24 \mathrm{~h}$ & HUVECs cultured in high glucose & {$[70,125]$} \\
\hline \multicolumn{5}{|c|}{ In vivo studies } \\
\hline EGb761 & $100,200 \mathrm{mg} / \mathrm{kg} / \mathrm{d}$ & p.o. 6 weeks & Obesity and insulin-resistant rats & [98] \\
\hline Rutin & $35,70 \mathrm{mg} / \mathrm{kg} / \mathrm{d}$ & p.o. 12 weeks & SD rats fed with high glucose & {$[101]$} \\
\hline TMP & $10,25,50 \mathrm{mg} / \mathrm{kg}$ & i.p. 2 weeks & STZ-induced diabetic mice & {$[110]$} \\
\hline DBT & $3,6 \mathrm{~g} / \mathrm{kg} / \mathrm{d}$ & p.o. 4 weeks & Nitric oxide inhibition plus high-fat diet-fed rats & {$[111]$} \\
\hline DBT & $3,6 \mathrm{~g} / \mathrm{kg} / \mathrm{d}$ & p.o. 4 weeks & Nitric oxide inhibition plus high-fat diet rats & {$[112]$} \\
\hline GGDGT & $200 \mathrm{mg} / \mathrm{kg} / \mathrm{d}$ & p.o. 12 weeks & Western diet-fed ApoE-/- mice & {$[113]$} \\
\hline Salvianolic acid B & $80,160 \mathrm{mg} / \mathrm{kg} / \mathrm{d}$ & p.o. 6 weeks & STZ-induced diabetic atherosclerosis & {$[120]$} \\
\hline Catalpol & $5 \mathrm{mg} / \mathrm{kg} / \mathrm{d}$ & p.o. 12 weeks & Hyperlipidemic diet plus alloxan diabetic-induced rabbit & [123] \\
\hline
\end{tabular}

HUVECs: human umbilical vein endothelial cells; HACEs: human aortic endothelial cells; bEnd.3: murine brain microvascular cell line; HMECs: microvascular endothelial cells; DBT: Danggui-Buxue-Tang; GGDGT: Galgeun-dang-gwi-tang; STZ: streptozotocin.

curcumin twice daily for 28 days [129]. Usharani et al. [130] showed that administration of a standardized preparation of curcuminoids (NCB-02, two capsules containing $150 \mathrm{mg}$ curcumin, twice daily) for 8 weeks significantly improved the endothelial function of patients with type 2 diabetes mellitus. Curcumin also blocks oxidative stress and inflammation by modulating PPAR $\gamma$ and Nrf2 activity [131]. Zheng et al. showed that the curcumin analogue L3 alleviates dyslipidaemia and hyperglycemia and reduces oxidative stress in diabetic mice induced by STZ and a high-fat diet. Additionally, L3 effectively decreases lectin-like oxidized low-density lipoprotein receptor-1 expression in the aortic arch. These results suggested that curcumin ameliorates diabetic atherosclerosis through multiple mechanisms [132].

\section{Future Perspectives}

Insulin resistance and hyperglycemia are associated with diabetic atherosclerosis, and endothelial dysfunction, vascular inflammation, myeloid cell recruitment, oxidative stress, VSMC phenotype changes, and platelet hyperreactivity all contribute to diabetic atherosclerosis. As reported recently, crosstalk between macrophage polarization and autophagy may be involved in diabetes and related atherosclerosis complications $[133,134]$. Extensive preclinical studies have identified the molecule targets and herbs that act on these targets as potential therapeutic agents for the management of diabetic atherosclerosis (see Table 2). However, currently, most clinical studies have small sample sizes and are not performed using a randomised design. The lack of high-quality clinical trials hampers the application of herbal medicines in patients with diabetic atherosclerosis. Therefore, more rigorous clinical trials of herbs on diabetic atherosclerosis, with large sample sizes and a randomised, controlled design, are needed. Furthermore, detection of new molecules and signalling cascades that regulate diabetes and atherosclerosis will help to improve treatment approaches owing to the multifaceted characteristics of diabetic atherosclerosis. Investigation of the mechanisms of multitargeted effects of herbs will also help to establish novel drugs for the treatment of diabetes and diabetic atherosclerosis. In the future, the combination of herb with western medicine may also facilitate the treatment of diabetic atherosclerosis. Thus, further studies on drug interactions and safety are needed.

\section{Conflicts of Interest}

The authors have no conflict of interest to declare.

\section{Authors' Contributions}

Yue Liu conceived the topic and helped in drafting the paper. Shuzheng Lyu helped in revising the manuscript. Jinfan Tian searched the literature and wrote the manuscript together with Yanfei Liu, and they are co-first authors. Keji Chen helped in drafting the manuscript. All authors read and approved the final manuscript.

\section{Acknowledgments}

The authors gratefully acknowledge the financial support from Beijing NOVA Program (no. Z171100001117027) and Key Projects in the National Science and Technology Pillar Program during the 12th Five-Year Plan Period of China (no. 2011BAl11B05). 


\section{References}

[1] M. Haneda, D. Koya, M. Isono, and R. Kikkawa, "Overview of glucose signaling in mesangial cells in diabetic nephropathy," Journal of the American Society of Nephrology, vol. 14, no. 5, pp. 1374-1382, 2003.

[2] C. Liu and Y. Huang, "Chinese herbal medicine on cardiovascular diseases and the mechanisms of action," Frontiers in Pharmacology, vol. 7, p. 469, 2016.

[3] J. Li, T. Casteels, T. Frogne et al., "Artemisinins target GABAA receptor signaling and impair alpha cell identity," Cell, vol. 168, no. 1-2, pp. 86-100, 2017.

[4] L. A. Johnson, H. S. Kim, M. J. Knudson, C. T. Nipp, X. Yi, and N. Maeda, "Diabetic atherosclerosis in APOE*4 mice: synergy between lipoprotein metabolism and vascular inflammation," Journal of Lipid Research, vol. 54, no. 2, pp. 386-396, 2013.

[5] H. Sun, X. Zhang, L. Zhao et al., "Attenuation of atherosclerotic lesions in diabetic apolipoprotein E-deficient mice using gene silencing of macrophage migration inhibitory factor," Journal of Cellular and Molecular Medicine, vol. 19, no. 4, pp. 836-849, 2015.

[6] J. E. Kanter, F. Kramer, S. Barnhart et al., "Diabetes promotes an inflammatory macrophage phenotype and atherosclerosis through acyl-CoA synthetase 1," Proceedings of the National Academy of Sciences of the United States of America, vol. 109, no. 12, pp. E715-E724, 2012.

[7] E. M. Bradshaw, K. Raddassi, W. Elyaman et al., "Monocytes from patients with type 1 diabetes spontaneously secrete proinflammatory cytokines inducing Th17 cells," Journal of Immunology, vol. 183, no. 7, pp. 4432-4439, 2009.

[8] G. M. Pieper, P. Langenstroer, and W. Siebeneich, "Diabeticinduced endothelial dysfunction in rat aorta: role of hydroxyl radicals," Cardiovascular Research, vol. 34, no. 1, pp. 145156, 1997.

[9] I. A. van den Oever, H. G. Raterman, M. T. Nurmohamed, and S. Simsek, "Endothelial dysfunction, inflammation, and apoptosis in diabetes mellitus," Mediators of Inflammation, vol. 2010, Article ID 792393, 15 pages, 2010.

[10] M. Y. Donath and T. Mandrup-Poulsen, "The use of interleukin-1-receptor antagonists in the treatment of diabetes mellitus," Nature Clinical Practice. Endocrinology \& Metabolism, vol. 4, no. 5, pp. 240-241, 2008.

[11] S. Vallejo, E. Palacios, T. Romacho, L. Villalobos, C. Peiró, and C. F. Sánchez-Ferrer, "The interleukin-1 receptor antagonist anakinra improves endothelial dysfunction in streptozotocin-induced diabetic rats," Cardiovascular Diabetology, vol. 13, p. 158, 2014.

[12] G. P. Chen, X. Q. Zhang, T. Wu, L. Li, J. Han, and C. Q. $\mathrm{Du}$, "Alteration of mevalonate pathway in proliferated vascular smooth muscle from diabetic mice: possible role in high-glucose-induced atherogenic process," Journal of Diabetes Research, vol. 2015, Article ID 379287, 11 pages, 2015.

[13] G. Orasanu and J. Plutzky, "The pathologic continuum of diabetic vascular disease," Journal of the American College of Cardiology, vol. 53, Supplement 5, pp. S35S42, 2009.

[14] E. Di Marco, S. P. Gray, K. Kennedy et al., "NOX4-derived reactive oxygen species limit fibrosis and inhibit proliferation of vascular smooth muscle cells in diabetic atherosclerosis," Free Radical Biology \& Medicine, vol. 97, pp. 556-567, 2016.
[15] J. M. Gerrard, M. J. Stuart, G. H. Rao et al., "Alteration in the balance of prostaglandin and thromboxane synthesis in diabetic rats," The Journal of Laboratory and Clinical Medicine, vol. 95, no. 6, pp. 950-958, 1980.

[16] P. A. Modesti, A. Fortini, G. F. Gensini, D. Vanni, D. Prisco, and R. Abbate, "Human prostacyclin platelet receptors in diabetes mellitus," Thrombosis Research, vol. 63, no. 5, pp. 541-548, 1991.

[17] P. Ferroni, S. Basili, A. Falco, and G. Davì, "Platelet activation in type 2 diabetes mellitus," Journal of Thrombosis and Haemostasis, vol. 2, no. 8, pp. 1282-1291, 2004.

[18] W. Wang, W. B. Lau, Y. Wang, X. Ma, and R. Li, "Reduction of CTRP9, a novel anti-platelet adipokine, contributes to abnormal platelet activity in diabetic animals," Cardiovascular Diabetology, vol. 15, p. 6, 2016.

[19] I. A. Sobenin, V. V. Tertov, A. N. Orekhov, and V. N. Smirnov, "Synergetic effect of desialylated and glycated low density lipoproteins on cholesterol accumulation in cultured smooth muscle intimal cells," Atherosclerosis, vol. 89, no. 2-3, pp. 151-154, 1991.

[20] N. Younis, R. Sharma, H. Soran, V. Charlton-Menys, M. Elseweidy, and P. N. Durrington, "Glycation as an atherogenic modification of LDL," Current Opinion in Lipidology, vol. 19, no. 4, pp. 378-384, 2008.

[21] A. M. Schmidt, O. Hori, J. X. Chen et al., “Advanced glycation endproducts interacting with their endothelial receptor induce expression of vascular cell adhesion molecule-1 (VCAM-1) in cultured human endothelial cells and in mice. A potential mechanism for the accelerated vasculopathy of diabetes," The Journal of Clinical Investigation, vol. 96, no. 3, pp. 1395-1403, 1995.

[22] S. Del Turco and G. Basta, "An update on advanced glycation endproducts and atherosclerosis," BioFactors, vol. 38, no. 4, pp. 266-274, 2012.

[23] K. Fukami, S. Yamagishi, and S. Okuda, "Role of AGEsRAGE system in cardiovascular disease," Current Pharmaceutical Design, vol. 20, no. 14, pp. 2395-2402, 2014.

[24] S. Menini, C. Lacobini, C. Ricci et al., "D-carnosine octylester attenuates atherosclerosis and renal disease in ApoE null mice fed a Western diet through reduction of carbonyl stress and inflammation," British Journal of Pharmacology, vol. 166, no. 4, pp. 1344-1356, 2012.

[25] S. Menini, C. Iacobini, C. Ricci, C. Blasetti Fantauzzi, and G. Pugliese, "Protection from diabetes-induced atherosclerosis and renal disease by D-carnosine-octylester: effects of early vs late inhibition of advanced glycation end-products in Apoe-null mice," Diabetologia, vol. 58, no. 4, pp. 845-853, 2015.

[26] L. Zhu, Z. He, F. Wu et al., "Immunization with advanced glycation end products modified low density lipoprotein inhibits atherosclerosis progression in diabetic apoE and LDLR null mice," Cardiovascular Diabetology, vol. 13, p. 151, 2014.

[27] Y. Naka, L. G. Bucciarelli, T. Wendt et al., "RAGE axis: animal models and novel insights into the vascular complications of diabetes," Arteriosclerosis, Thrombosis, and Vascular Biology, vol. 24, no. 8, pp. 1342-1349, 2004.

[28] K. B. Rubinow, V. Z. Wall, J. Nelson et al., "Acyl-CoA synthetase 1 is induced by Gram-negative bacteria and lipopolysaccharide and is required for phospholipid turnover in stimulated macrophages," The Journal of Biological Chemistry, vol. 288, no. 14, pp. 9957-9970, 2013. 
[29] J. E. Kanter, C. Tang, J. F. Oram, and K. E. Bornfeldt, "Acyl-CoA synthetase 1 is required for oleate and linoleate mediated inhibition of cholesterol efflux through ATP-binding cassette transporter A1 in macrophages," Biochimica et Biophysica Acta (BBA) - Molecular and Cell Biology of Lipids, vol. 1821, no. 3, pp. 358-364, 2012.

[30] M. Pan, A. I. Cederbaum, Y. L. Zhang, H. N. Ginsberg, K. J. Williams, and E. A. Fisher, "Lipid peroxidation and oxidant stress regulate hepatic apolipoprotein B degradation and VLDL production," The Journal of Clinical Investigation, vol. 113, no. 9, pp. 1277-1287, 2004.

[31] M. Wegner, M. Pioruńska-Stolzmann, A. Araszkiewicz, D. Zozulińska-Ziółkiewicz, and B. Wierusz-Wysocka, "Evaluation of paraoxonase 1 arylesterase activity and lipid peroxide levels in patients with type 1 diabetes," Polskie Archiwum Medycyny Wewnętrznej, vol. 121, no. 12, pp. 448-454, 2011.

[32] D. K. Spady, "Reverse cholesterol transport and atherosclerosis regression," Circulation, vol. 100, no. 6, pp. 576-578, 1999.

[33] S. R. Zatalia and H. Sanusi, "The role of antioxidants in the pathophysiology, complications, and management of diabetes mellitus," Acta Medica Indonesiana, vol. 45, no. 2, pp. 141-147, 2013.

[34] S. Taş, E. Sarandöl, and M. Dirican, "Vitamin B6 supplementation improves oxidative stress and enhances serum paraoxonase/arylesterase activities in streptozotocin-induced diabetic rats," The Scientific World Journal, vol. 2014, Article ID 351598, 7 pages, 2014.

[35] M. A. Nauck, M. M. Heimesaat, C. Orskov, J. J. Holst, R. Ebert, and W. Creutzfeldt, "Preserved incretin activity of glucagon-like peptide 1 [7-36 amide] but not of synthetic human gastric inhibitory polypeptide in patients with type- 2 diabetes mellitus," The Journal of Clinical Investigation, vol. 91, no. 1, pp. 301-307, 1993.

[36] Y. Nogi, M. Nagashima, M. Terasaki, K. Nohtomi, T. Watanabe, and T. Hirano, "Glucose-dependent insulinotropic polypeptide prevents the progression of macrophage-driven atherosclerosis in diabetic apolipoprotein E-null mice," PLoS One, vol. 7, no. 4, article e35683, 2012.

[37] E. Distel, T. J. Barrett, K. Chung et al., "miR33 inhibition overcomes deleterious effects of diabetes mellitus on atherosclerosis plaque regression in mice," Circulation Research, vol. 115, no. 9, pp. 759-769, 2014.

[38] L. M. Villeneuve, M. Kato, M. A. Reddy, M. Wang, L. Lanting, and R. Natarajan, "Enhanced levels of microRNA-125b in vascular smooth muscle cells of diabetic $\mathrm{db} / \mathrm{db}$ mice lead to increased inflammatory gene expression by targeting the histone methyltransferase Suv39h1," Diabetes, vol. 59, no. 11, pp. 2904-2915, 2010.

[39] M. A. Reddy, W. Jin, L. Villeneuve et al., "Pro-inflammatory role of microrna-200 in vascular smooth muscle cells from diabetic mice," Arteriosclerosis, Thrombosis, and Vascular Biology, vol. 32, no. 3, pp. 721-729, 2012.

[40] M. A. Reddy, S. Das, C. Zhuo et al., "Regulation of vascular smooth muscle cell dysfunction under diabetic conditions by miR-504," Arteriosclerosis, Thrombosis, and Vascular Biology, vol. 36, no. 5, pp. 864-873, 2016.

[41] J. Xu, L. Li, H. F. Yun, and Y. S. Han, "MiR-138 promotes smooth muscle cells proliferation and migration in $\mathrm{db} / \mathrm{db}$ mice through down-regulation of SIRT1," Biochemical and Biophysical Research Communications, vol. 463, no. 4, pp. 1159-1164, 2015.
[42] H. Oberkofler, A. Pfeifenberger, S. Soyal et al., "Aberrant hepatic TRIB3 gene expression in insulin-resistant obese humans," Diabetologia, vol. 53, no. 9, pp. 1971-1975, 2010.

[43] N. Ohoka, S. Yoshii, T. Hattori, K. Onozaki, and H. Hayashi, "TRB3, a novel ER stress-inducible gene, is induced via ATF4-CHOP pathway and is involved in cell death," The EMBO Journal, vol. 24, no. 6, pp. 1243-1255, 2005.

[44] J. Liu, X. Wu, J. L. Franklin et al., "Mammalian Tribbles homolog 3 impairs insulin action in skeletal muscle: role in glucose-induced insulin resistance," American Journal of Physiology. Endocrinology and Metabolism, vol. 298, no. 3, pp. E565-E576, 2010.

[45] K. Du, S. Herzig, R. N. Kulkarni, and M. Montminy, “TRB3: a tribbles homolog that inhibits Akt/PKB activation by insulin in liver," Science, vol. 300, no. 5625, pp. 1574-1577, 2003.

[46] J. R. Sowers, "Role of TRIB3 in diabetic and overnutritioninduced atherosclerosis," Diabetes, vol. 61, no. 2, pp. 265266, 2012.

[47] A. Whaley-Connell and J. R. Sowers, "Indices of obesity and cardiometabolic risk," Hypertension, vol. 58, no. 6, pp. 991993, 2011.

[48] L. Qi, J. E. Heredia, J. Y. Altarejos et al., “TRB3 links the E3 ubiquitin ligase COP1 to lipid metabolism," Science, vol. 312, no. 5781, pp. 1763-1766, 2006.

[49] Z. H. Wang, Y. Y. Shang, S. Zhang et al., "Silence of TRIB3 suppresses atherosclerosis and stabilizes plaques in diabetic ApoE $^{-/-} /$LDL receptor ${ }^{-/-}$mice," Diabetes, vol. 61, no. 2, pp. 463-473, 2012.

[50] G. Miklossy, T. S. Hilliard, and J. Turkson, "Therapeutic modulators of STAT signalling for human diseases," Nature Reviews. Drug Discovery, vol. 12, no. 8, pp. 611-629, 2013.

[51] M. B. Marrero, "Introduction to JAK/STAT signaling and the vasculature," Vascular Pharmacology, vol. 43, no. 5, pp. 307-309, 2005.

[52] T. Tamiya, I. Kashiwagi, R. Takahashi, H. Yasukawa, and A. Yoshimura, "Suppressors of cytokine signaling (SOCS) proteins and JAK/STAT pathways: regulation of T-cell inflammation by SOCS1 and SOCS3," Arteriosclerosis, Thrombosis, and Vascular Biology, vol. 31, no. 5, pp. 980985, 2011.

[53] S. Agrawal, M. Febbraio, E. Podrez, M. K. Cathcart, G. R. Stark, and G. M. Chisolm, "Signal transducer and activator of transcription 1 is required for optimal foam cell formation and atherosclerotic lesion development," Circulation, vol. 115, no. 23, pp. 2939-2947, 2007.

[54] N. M. Gharavi, J. A. Alva, K. P. Mouillesseaux et al., "Role of the Jak/STAT pathway in the regulation of interleukin- 8 transcription by oxidized phospholipids in vitro and in atherosclerosis in vivo," The Journal of Biological Chemistry, vol. 282, no. 43, pp. 31460-31468, 2007.

[55] W. S. Lim, J. M. Timmins, T. A. Seimon et al., "Signal transducer and activator of transcription- 1 is critical for apoptosis in macrophages subjected to endoplasmic reticulum stress in vitro and in advanced atherosclerotic lesions in vivo," Circulation, vol. 117, no. 7, pp. 940-951, 2008.

[56] D. Torella, A. Curcio, C. Gasparri et al., "Fludarabine prevents smooth muscle proliferation in vitro and neointimal hyperplasia in vivo through specific inhibition of STAT-1 activation," American Journal of Physiology. Heart and Circulatory Physiology, vol. 292, no. 6, pp. H2935-H2943, 2007. 
[57] J. M. Daniel, J. Dutzmann, W. Bielenberg et al., "Inhibition of STAT3 signaling prevents vascular smooth muscle cell proliferation and neointima formation," Basic Research in Cardiology, vol. 107, no. 3, p. 261, 2012.

[58] M. B. Marrero, A. K. Banes-Berceli, D. M. Stern, and D. C. Eaton, "Role of the JAK/STAT signaling pathway in diabetic nephropathy," American Journal of Physiology. Renal Physiology, vol. 290, no. 4, pp. F762-F768, 2006.

[59] J. Hu, X. Fan, X. Meng, Y. Wang, Q. Liang, and G. Luo, "Evidence for the involvement of JAK/STAT/SOCS pathway in the mechanism of Tangshen formula-treated diabetic nephropathy," Planta Medica, vol. 80, no. 8-9, pp. 614-621, 2014.

[60] D. Suchy, K. Łabuzek, G. Machnik, M. Kozłowski, and B. Okopień, "SOCS and diabetes-ups and downs of a turbulent relationship," Cell Biochemistry and Function, vol. 31, no. 3, pp. 181-195, 2013.

[61] Q. Zhao, C. Gao, and Z. Cui, "Ginkgolide A reduces inflammatory response in high-glucose-stimulated human umbilical vein endothelial cells through STAT3-mediated pathway," International Immunopharmacology, vol. 25, no. 2, pp. 242-248, 2015.

[62] A. Yoshimura, T. Naka, and M. Kubo, "SOCS proteins, cytokine signalling and immune regulation," Nature Reviews. Immunology, vol. 7, no. 6, pp. 454-465, 2007.

[63] H. Kiu and S. E. Nicholson, "Biology and significance of the JAK/STAT signalling pathways," Growth Factors, vol. 30, no. 2, pp. 88-106, 2012.

[64] C. Recio, A. Oguiza, I. Lazaro, B. Mallavia, J. Egido, and C. Gomez-Guerrero, "Suppressor of cytokine signaling 1derived peptide inhibits Janus kinase/signal transducers and activators of transcription pathway and improves inflammation and atherosclerosis in diabetic mice," Arteriosclerosis, Thrombosis, and Vascular Biology, vol. 34, no. 9, pp. 19531960, 2014.

[65] H. B. Peng, P. Libby, and J. K. Liao, "Induction and stabilization of I kappa B alpha by nitric oxide mediates inhibition of NF-kappa B," The Journal of Biological Chemistry, vol. 270, no. 23, pp. 14214-14219, 1995.

[66] G. P. Fadini, M. Miorin, M. Facco et al., "Circulating endothelial progenitor cells are reduced in peripheral vascular complications of type 2 diabetes mellitus," Journal of the American College of Cardiology, vol. 45, no. 9, pp. 1449-1457, 2005.

[67] Y. H. Chen, S. J. Lin, F. Y. Lin et al., "High glucose impairs early and late endothelial progenitor cells by modifying nitric oxide-related but not oxidative stress-mediated mechanisms," Diabetes, vol. 56, no. 6, pp. 1559-1568, 2007.

[68] N. Sun, H. Wang, and L. Wang, "Vaspin alleviates dysfunction of endothelial progenitor cells induced by high glucose via PI3K/Akt/eNOS pathway," International Journal of Clinical and Experimental Pathology, vol. 8, no. 1, pp. 482489, 2015.

[69] N. Ouchi, H. Kobayashi, S. Kihara et al., "Adiponectin stimulates angiogenesis by promoting cross-talk between AMP-activated protein kinase and Akt signaling in endothelial cells," The Journal of Biological Chemistry, vol. 279, no. 2, pp. 1304-1309, 2004.

[70] J. Yang, N. Wang, Y. Zhu, and P. Feng, "Roles of SIRT1 in high glucose-induced endothelial impairment: association with diabetic atherosclerosis," Archives of Medical Research, vol. 42, no. 5, pp. 354-360, 2011.
[71] N. L. Price, A. P. Gomes, A. J. Ling et al., "SIRT1 is required for AMPK activation and the beneficial effects of resveratrol on mitochondrial function," Cell Metabolism, vol. 15, no. 5, pp. 675-690, 2012.

[72] J. Chen, M. Dai, and Y. Wang, "Paeonol inhibits proliferation of vascular smooth muscle cells stimulated by high glucose via Ras-Raf-ERK1/2 signaling pathway in coculture model," Evidence-Based Complementary and Alternative Medicine, vol. 2014, Article ID 484269, 9 pages, 2014.

[73] Y. Mebratu and Y. Tesfaigzi, "How ERK1/2 activation controls cell proliferation and cell death: is subcellular localization the answer?" Cell Cycle, vol. 8, no. 8, pp. 1168-1175, 2009.

[74] Y. Zhao, J. Liu, L. Li, L. Liu, and L. Wu, "Role of Ras/PKCzeta/ MEK/ERK1/2 signaling pathway in angiotensin II-induced vascular smooth muscle cell proliferation," Regulatory Peptides, vol. 128, no. 1, pp. 43-50, 2005.

[75] D. Popov, M. Nemecz, M. Dumitrescu, A. Georgescu, and F. D. Böhmer, "Long-term high glucose concentration influences Akt, ERK1/2, and PTP1B protein expression in human aortic smooth muscle cells," Biochemical and Biophysical Research Communications, vol. 388, no. 1, pp. 51-55, 2009.

[76] S. Kuki, T. Imanishi, K. Kobayashi, Y. Matsuo, M. Obana, and T. Akasaka, "Hyperglycemia accelerated endothelial progenitor cell senescence via the activation of p38 mitogenactivated protein kinase," Circulation Journal, vol. 70, no. 8, pp. 1076-1081, 2006.

[77] F. Jansen, X. Yang, B. S. Franklin et al., "High glucose condition increases NADPH oxidase activity in endothelial microparticles that promote vascular inflammation," Cardiovascular Research, vol. 98, no. 1, pp. 94-106, 2013.

[78] M. C. Durpès, C. Morin, J. Paquin-Veillet et al., "PKC-beta activation inhibits IL-18-binding protein causing endothelial dysfunction and diabetic atherosclerosis," Cardiovascular Research, vol. 106, no. 2, pp. 303-313, 2015.

[79] P. Geraldes and G. L. King, "Activation of protein kinase $\mathrm{C}$ isoforms and its impact on diabetic complications," Circulation Research, vol. 106, no. 8, pp. 1319-1331, 2010.

[80] G. Ceolotto, A. Gallo, I. Papparella et al., "Rosiglitazone reduces glucose-induced oxidative stress mediated by NAD (P) H oxidase via AMPK-dependent mechanism," Arteriosclerosis, Thrombosis, and Vascular Biology, vol. 27, no. 12, pp. 2627-2633, 2007.

[81] L. Kong, X. Shen, L. Lin et al., "PKCbeta promotes vascular inflammation and acceleration of atherosclerosis in diabetic ApoE null mice," Arteriosclerosis, Thrombosis, and Vascular Biology, vol. 33, no. 8, pp. 1779-1787, 2013.

[82] Z. Levi, A. Shaish, N. Yacov et al., "Rosiglitazone (PPARgamma-agonist) attenuates atherogenesis with no effect on hyperglycaemia in a combined diabetes-atherosclerosis mouse model," Diabetes, Obesity \& Metabolism, vol. 5, no. 1, pp. 45-50, 2003.

[83] Z. Bagi, A. Koller, and G. Kaley, "PPARgamma activation, by reducing oxidative stress, increases NO bioavailability in coronary arterioles of mice with type 2 diabetes," American Journal of Physiology. Heart and Circulatory Physiology, vol. 286, no. 2, pp. H742-H748, 2004.

[84] B. B. Di, H. W. Li, W. P. Li, X. H. Shen, Z. J. Sun, and X. Wu, "Pioglitazone inhibits high glucose-induced expression of receptor for advanced glycation end products in coronary artery smooth muscle cells," Molecular Medicine Reports, vol. 11, no. 4, pp. 2601-2607, 2015. 
[85] I. Osman and L. Segar, "Pioglitazone, a PPARgamma agonist, attenuates PDGF-induced vascular smooth muscle cell proliferation through AMPK-dependent and AMPK-independent inhibition of mTOR/p70S6K and ERK signaling," Biochemical Pharmacology, vol. 101, pp. 54-70, 2016.

[86] G. Chinetti, S. Lestavel, V. Bocher et al., "PPAR-alpha and PPAR-gamma activators induce cholesterol removal from human macrophage foam cells through stimulation of the ABCA1 pathway," Nature Medicine, vol. 7, no. 1, pp. 53-58, 2001.

[87] K. J. Moore, E. D. Rosen, M. L. Fitzgerald et al., "The role of PPAR-gamma in macrophage differentiation and cholesterol uptake," Nature Medicine, vol. 7, no. 1, pp. 41-47, 2001.

[88] G. C. Amberg, C. F. Rossow, M. F. Navedo, and L. F. Santana, "NFATc3 regulates Kv2.1 expression in arterial smooth muscle," The Journal of Biological Chemistry, vol. 279, no. 45, pp. 47326-47334, 2004.

[89] J. Nilsson, L. M. Nilsson, Y. W. Chen, J. D. Molkentin, D. Erlinge, and M. F. Gomez, "High glucose activates nuclear factor of activated T cells in native vascular smooth muscle," Arteriosclerosis, Thrombosis, and Vascular Biology, vol. 26, no. 4, pp. 794-800, 2006.

[90] L. M. Nilsson-Berglund, A. V. Zetterqvist, J. Nilsson-Ohman et al., "Nuclear factor of activated T cells regulates osteopontin expression in arterial smooth muscle in response to diabetesinduced hyperglycemia," Arteriosclerosis, Thrombosis, and Vascular Biology, vol. 30, no. 2, pp. 218-224, 2010.

[91] A. V. Zetterqvist, L. M. Berglund, F. Blanco et al., "Inhibition of nuclear factor of activated T-cells (NFAT) suppresses accelerated atherosclerosis in diabetic mice," PLoS One, vol. 8, no. 6, article e65020, 2014.

[92] Z. Ungvari, L. Bailey-Downs, T. Gautam et al., "Adaptive induction of NF-E2-related factor-2-driven antioxidant genes in endothelial cells in response to hyperglycemia," American Journal of Physiology. Heart and Circulatory Physiology, vol. 300, no. 4, pp. H1133-H1140, 2011.

[93] S. M. Tan and J. B. Haande, "Combating oxidative stress in diabetic complications with Nrf2 activators: how much is too much?" Redox Report, vol. 19, no. 3, pp. 107-117, 2014.

[94] D. Cheng, B. Liang, and Y. Li, "Antihyperglycemic effect of Ginkgo biloba extract in streptozotocin-induced diabetes in rats," BioMed Research International, vol. 2013, Article ID 162724, 7 pages, 2013.

[95] G. Liu, M. Grifman, J. Macdonald, P. Moller, F. Wong-Staal, and Q. X. Li, "Isoginkgetin enhances adiponectin secretion from differentiated adiposarcoma cells via a novel pathway involving AMP-activated protein kinase," The Journal of Endocrinology, vol. 194, no. 3, pp. 569-578, 2007.

[96] L. Zhou, Q. Meng, T. Qian, and Z. Yang, “Ginkgo biloba extract enhances glucose tolerance in hyperinsulinisminduced hepatic cells," Journal of Natural Medicines, vol. 65, no. 1, pp. 50-56, 2011.

[97] X. Li, Y. Hu, Y. Fu, Y. Ying, and G. Chen, "Effect of Ginkgo biloba extract on glucose uptake of diaphragm in diabetic rats," Zhongguo Zhong Yao Za Zhi, vol. 35, no. 3, pp. 356359, 2010, [Article in Chinese].

[98] S. Lim, J. W. Yoon, S. M. Kang et al., "EGb761, a Ginkgo biloba extract, is effective against atherosclerosis in vitro, and in a rat model of type 2 diabetes," PLoS One, vol. 6, no. 6, article e20301, 2011.
[99] M. Zhao, X. X. Wang, and W. H. Wan, "Effects of the ginkgo biloba extract on the superoxide dismutase activity and apoptosis of endothelial progenitor cells from diabetic peripheral blood," Genetics and Molecular Research, vol. 13, no. 1, pp. 220-227, 2014.

[100] H. Y. Tsai, P. H. Huang, F. Y. Lin, J. S. Chen, S. J. Lin, and J. W. Chen, "Ginkgo biloba extract reduces highglucose-induced endothelial reactive oxygen species generation and cell adhesion molecule expression by enhancing HO-1 expression via Akt/eNOS and p38 MAP kinase pathways," European Journal of Pharmaceutical Sciences, vol. 48, no. 4-5, pp. 803-811, 2013.

[101] W. Wang, Q. H. Wu, Y. Sui, Y. Wang, and X. Qiu, "Rutin protects endothelial dysfunction by disturbing Nox4 and ROS-sensitive NLRP3 inflammasome," Biomedicine \& Pharmacotherapy, vol. 86, pp. 32-40, 2016.

[102] L. Lv, S. S. Jiang, J. Xu, J. B. Gong, and Y. Cheng, "Protective effect of ligustrazine against myocardial ischaemia reperfusion in rats: the role of endothelial nitric oxide synthase," Clinical and Experimental Pharmacology \& Physiology, vol. 39, no. 1, pp. 20-27, 2012.

[103] Q. Xu, B. Zhang, X. M. Li, and X. Gao, "Traditional Chinese medicine formula Qing Huo Yi Hao as superoxide anion scavenger in high glucose-treated endothelial cells," Acta Pharmacologica Sinica, vol. 33, no. 4, pp. 496-502, 2012.

[104] Y. Kang, M. Hu, Y. Zhu, X. Gao, and M. W. Wang, “Antioxidative effect of the herbal remedy Qin Huo Yi Hao and its active component tetramethylpyrazine on high glucosetreated endothelial cells," Life Sciences, vol. 84, no. 13-14, pp. 428-436, 2009.

[105] Q. Xu, P. Xia, X. Li, W. Wang, Z. Liu, and X. Gao, "Tetramethylpyrazine ameliorates high glucose-induced endothelial dysfunction by increasing mitochondrial biogenesis," PLoS One, vol. 9, no. 2, article e88243, 2014.

[106] S. Li, J. H. Wang, and S. L. Chen, "Inhibitory effect of ligustrazine on proliferation of rabbit vascular smooth muscle cells after arterial injury," Zhongguo Yao Li Xue Bao, vol. 20, no. 10, pp. 917-922, 1999.

[107] L. Yu, X. Huang, K. Huang, C. Gui, Q. Huang, and B. Wei, "Ligustrazine attenuates the platelet-derived growth factorBB-induced proliferation and migration of vascular smooth muscle cells by interrupting extracellular signal-regulated kinase and P38 mitogen-activated protein kinase pathways," Molecular Medicine Reports, vol. 12, no. 1, pp. 705-711, 2015.

[108] X. Y. Li, J. L. He, H. T. Liu, W. M. Li, and C. Yu, “Tetramethylpyrazine suppresses interleukin-8 expression in LPS-stimulated human umbilical vein endothelial cell by blocking ERK, p38 and nuclear factor-kappaB signaling pathways," Journal of Ethnopharmacology, vol. 125, no. 1, pp. 83-89, 2009.

[109] M. H. Gao, L. Zhang, B. Li, S. R. Ren, and B. Zhang, "Effect of tetramethylpyrazine on JAK-STAT signal transduction in cardiomyocyte hypertrophy," Xi Bao Yu Fen Zi Mian Yi Xue Za Zhi, vol. 27, no. 5, pp. 519-521, 524, 2011, [Article in Chinese].

[110] L. M. Lee, C. F. Liu, and P. P. Yang, "Effect of tetramethylpyrazine on lipid peroxidation in streptozotocin-induced diabetic mice," The American Journal of Chinese Medicine, vol. 30, no. 4, pp. 601-608, 2002.

[111] H. Zhang, S. Chen, X. Deng, X. Yang, and X. Huang, "Danggui-Buxue-Tang decoction has an anti-inflammatory 
effect in diabetic atherosclerosis rat model," Diabetes Research and Clinical Practice, vol. 74, no. 2, pp. 194-196, 2006.

[112] H. Zhang, S. Chen, X. Deng, X. Yang, and X. Huang, "The effects of Danggui-Buxue-Tang on blood lipid and expression of genes related to foam cell formation in the early stage of atherosclerosis in diabetic GK rats," Diabetes Research and Clinical Practice, vol. 77, no. 3, pp. 479-481, 2007.

[113] S. M. Lee, Y. J. Lee, J. H. Choi et al., "Gal-geun-dang-gwi-tang improves diabetic vascular complication in apolipoprotein $\mathrm{E}$ KO mice fed a western diet," BMC Complementary and Alternative Medicine, vol. 14, p. 453, 2014.

[114] Y. Joe, M. Zheng, H. J. Kim et al., "Salvianolic acid B exerts vasoprotective effects through the modulation of heme oxygenase-1 and arginase activities," The Journal of Pharmacology and Experimental Therapeutics, vol. 341, no. 3, pp. 850-858, 2012.

[115] J. H. Ho and C. Y. Hong, "Salvianolic acids: small compounds with multiple mechanisms for cardiovascular protection," Journal of Biomedical Science, vol. 18, p. 30, 2011.

[116] S. E. Lee, S. I. Jeong, H. Yang et al., "Extract of Salvia miltiorrhiza (Danshen) induces Nrf2-mediated heme oxygenase-1 expression as a cytoprotective action in RAW 264.7 macrophages," Journal of Ethnopharmacology, vol. 139, no. 2, pp. 541-548, 2012.

[117] H. J. Lee, M. Seo, and E. J. Lee, "Salvianolic acid B inhibits atherogenesis of vascular cells through induction of Nrf2dependent heme oxygenase-1," Current Medicinal Chemistry, vol. 21, no. 26, pp. 3095-3106, 2014.

[118] S. Raoufi, T. Baluchnejadmojarad, M. Roghani, T. Ghazanfari, F. Khojasteh, and M. Mansouri, "Antidiabetic potential of salvianolic acid B in multiple low-dose streptozotocininduced diabetes," Pharmaceutical Biology, vol. 53, no. 12, pp. 1803-1809, 2015.

[119] S. Qian, D. Huo, S. Wang, and Q. Qian, "Inhibition of glucose-induced vascular endothelial growth factor expression by Salvia miltiorrhiza hydrophilic extract in human microvascular endothelial cells: evidence for mitochondrial oxidative stress," Journal of Ethnopharmacology, vol. 137, no. 2, pp. 985-991, 2011.

[120] Y. Ren, S. Tao, S. Zheng et al., "Salvianolic acid B improves vascular endothelial function in diabetic rats with blood glucose fluctuations via suppression of endothelial cell apoptosis," European Journal of Pharmacology, vol. 791, pp. 308-315, 2016.

[121] J. P. Shieh, K. C. Cheng, H. H. Chung, Y. F. Kerh, C. H. Yeh, and J. T. Cheng, "Plasma glucose lowering mechanisms of catalpol, an active principle from roots of Rehmannia glutinosa, in streptozotocin-induced diabetic rats," Journal of Agricultural and Food Chemistry, vol. 59, no. 8, pp. 3747-3753, 2011.

[122] J. Y. Liu and D. J. Zhang, "Amelioration by catalpol of atherosclerotic lesions in hypercholesterolemic rabbits," Planta Medica, vol. 81, no. 3, pp. 175-184, 2015.

[123] J. Y. Liu, C. Z. Zheng, X. P. Hao, D. J. Zhang, A. W. Mao, and P. Yuan, "Catalpol ameliorates diabetic atherosclerosis in diabetic rabbits," American Journal of Translational Research, vol. 8, no. 10, pp. 4278-4288, 2016.

[124] B. N. Zordoky, I. M. Robertson, and J. R. Dyck, "Preclinical and clinical evidence for the role of resveratrol in the treatment of cardiovascular diseases," Biochimica et Biophysica Acta (BBA) - Molecular Basis of Disease, vol. 1852, no. 6, pp. 1155-1177, 2015.
[125] J. Yang, N. Wang, J. Li, J. Zhang, and P. Feng, "Effects of resveratrol on NO secretion stimulated by insulin and its dependence on SIRT1 in high glucose cultured endothelial cells," Endocrine, vol. 37, no. 2, pp. 365-372, 2010.

[126] Y. Zhang, Z. Luo, L. Ma, Q. Xu, Q. Yang, and L. Si, "Resveratrol prevents the impairment of advanced glycosylation end products (AGE) on macrophage lipid homeostasis by suppressing the receptor for AGE via peroxisome proliferatoractivated receptor gamma activation," International Journal of Molecular Medicine, vol. 25, no. 5, pp. 729-734, 2010.

[127] X. Hou, S. Xu, K. A. Maitland-Toolan et al., "SIRT1 regulates hepatocyte lipid metabolism through activating AMPactivated protein kinase," The Journal of Biological Chemistry, vol. 283, no. 29, pp. 20015-20026, 2008.

[128] M. Zang, S. Xu, K. A. Maitland-Toolan et al., "Polyphenols stimulate AMP-activated protein kinase, lower lipids, and inhibit accelerated atherosclerosis in diabetic LDL receptordeficient mice," Diabetes, vol. 55, no. 8, pp. 2180-2191, 2006.

[129] A. Ramirez Boscá, A. Soler, M. A. Carrión-Gutiérrez et al., "An hydroalcoholic extract of Curcuma longa lowers the abnormally high values of human-plasma fibrinogen," Mechanisms of Ageing and Development, vol. 114, no. 3, pp. 207-210, 2000.

[130] P. Usharani, A. A. Mateen, M. U. Naidu, Y. S. Raju, and N. Chandra, "Effect of NCB-02, atorvastatin and placebo on endothelial function, oxidative stress and inflammatory markers in patients with type 2 diabetes mellitus: a randomized, parallel-group, placebo-controlled, 8-week study," Drugs in $R$ \& D, vol. 9, no. 4, pp. 243-250, 2008.

[131] J. M. Zingg, S. T. Hasan, and M. Meydani, "Molecular mechanisms of hypolipidemic effects of curcumin," BioFactors, vol. 39, no. 1, pp. 101-121, 2013.

[132] B. Zheng, L. Yang, C. Wen et al., "Curcumin analog L3 alleviates diabetic atherosclerosis by multiple effects," European Journal of Pharmacology, vol. 775, pp. 22-34, 2016.

[133] M. Ouimet, "Autophagy in obesity and atherosclerosis: interrelationships between cholesterol homeostasis, lipoprotein metabolism and autophagy in macrophages and other systems," Biochimica et Biophysica Acta (BBA) - Molecular and Cell Biology of Lipids, vol. 1831, no. 6, pp. 1124-1133, 2013.

[134] F. Tian, B. L. Yu, and J. R. Hu, "mTOR mediates the crosstalk of macrophage polarization and autophagy in atherosclerosis," International Journal of Cardiology, vol. 177, no. 1, pp. 144-145, 2014. 


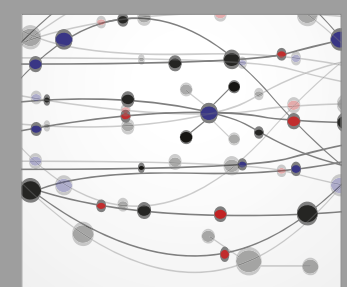

The Scientific World Journal
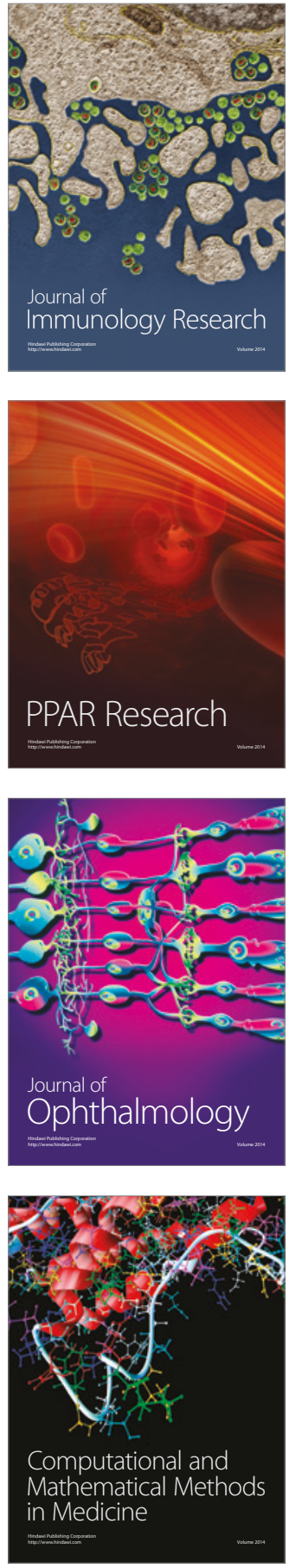

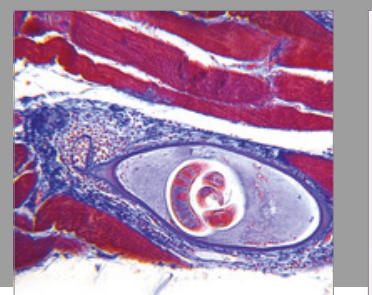

Gastroenterology Research and Practice
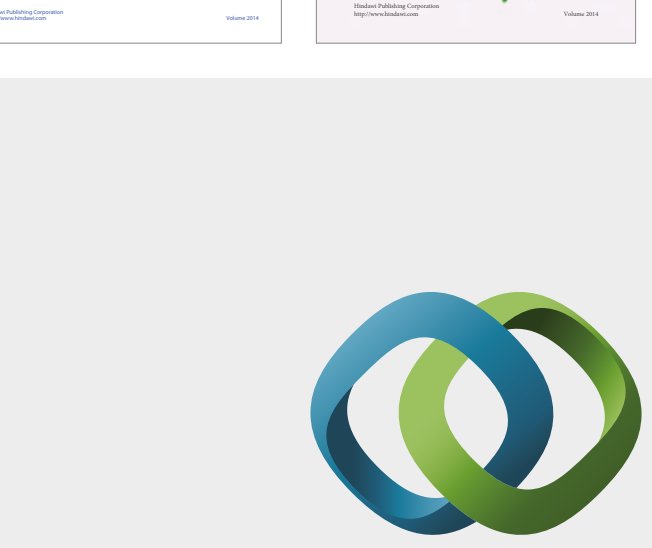

\section{Hindawi}

Submit your manuscripts at

https://www.hindawi.com
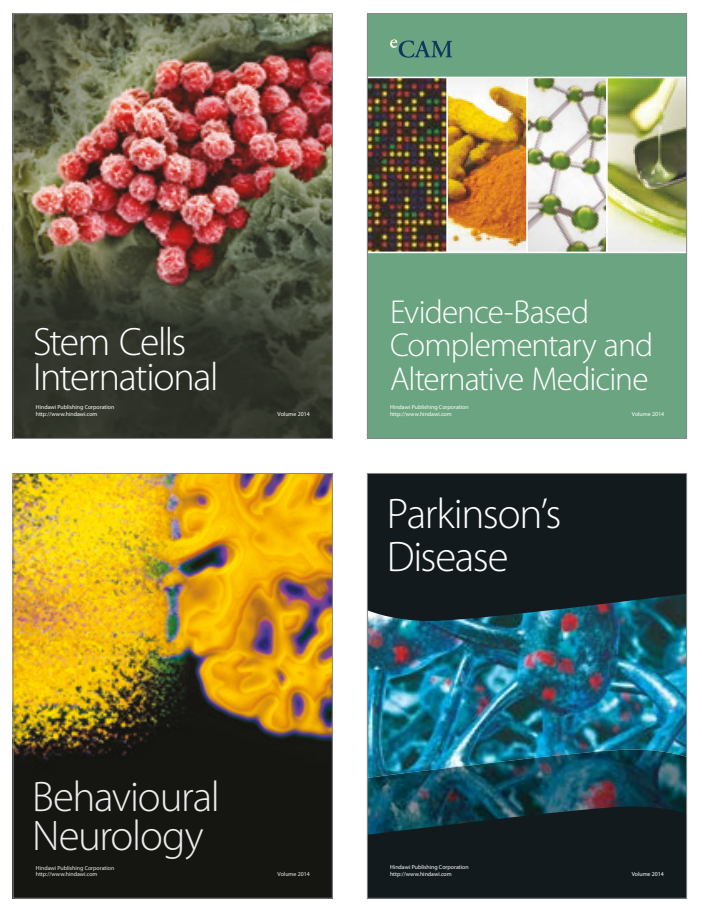
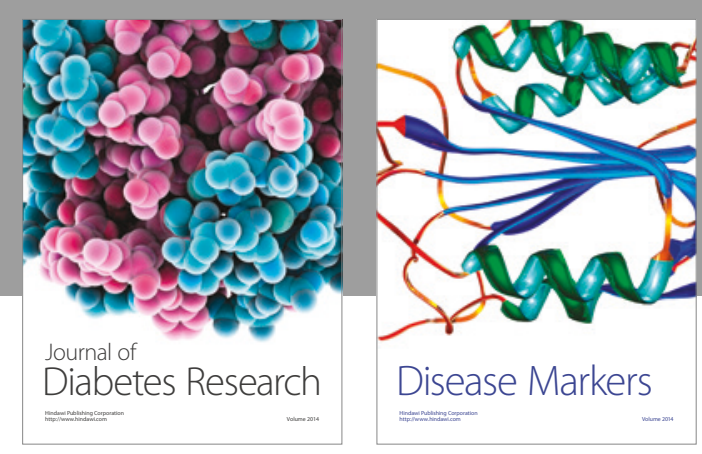

Disease Markers
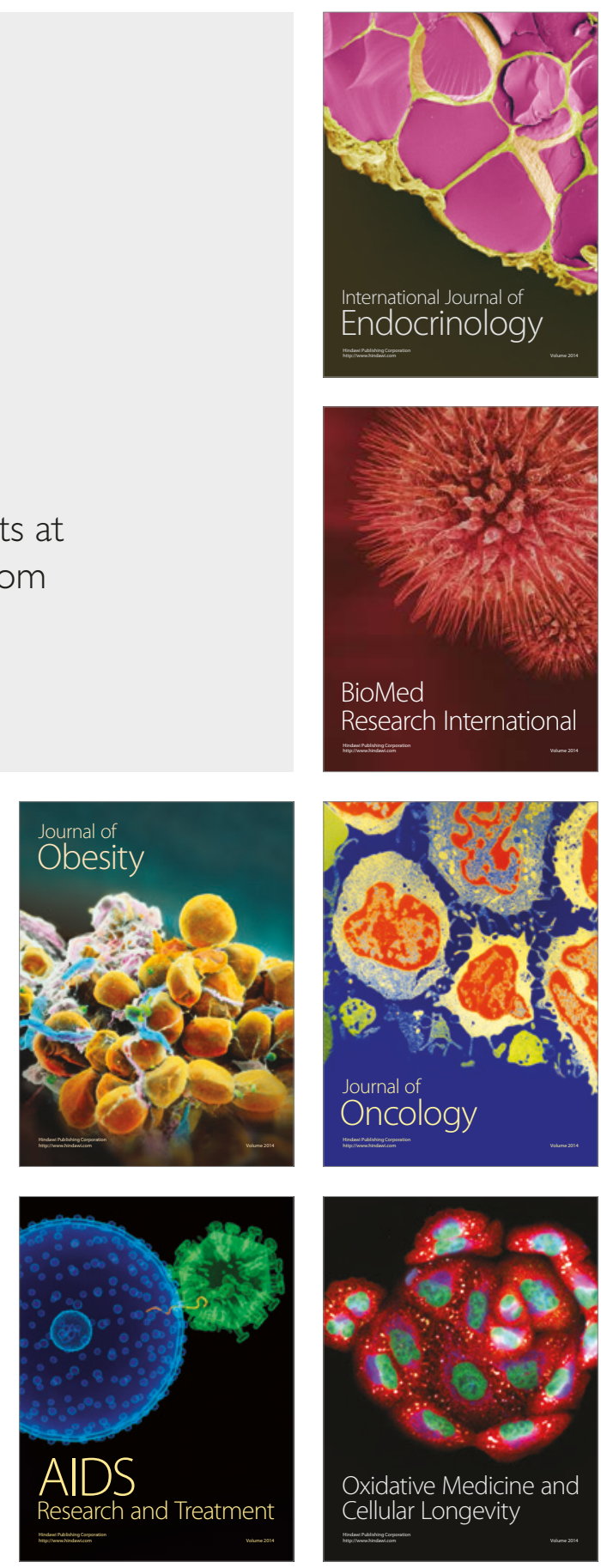